\section{Enhanced fatty acid oxidation in adipocytes and macrophages reduces lipid-induced triglyceride accumulation and inflammation}

Maria Ida Malandrino ${ }^{1,2}$, Raquel Fucho ${ }^{1,2}$, Minéia Weber ${ }^{1,2}$, María Calderon-

5 Dominguez ${ }^{1,2}$, Joan Francesc Mir $^{1,2}$, Lorea Valcarcel ${ }^{1,2}$, Xavier Escoté ${ }^{3,4}$, María Gómez-

6 Serrano $^{2,5}$, Belén Peral ${ }^{2,5}$, Laia Salvadó ${ }^{4,6}$, Sonia Fernández-Veledo ${ }^{3,4}$, Núria Casals ${ }^{2,7}$,

Manuel Vázquez-Carrera ${ }^{4,6}$, Francesc Villarroya ${ }^{1,2}$, Joan J Vendrell ${ }^{3,4}$, Dolors Serra ${ }^{1,2}$,

Laura Herrero ${ }^{1,2}$

9

${ }^{1}$ Department of Biochemistry and Molecular Biology, Institut de Biomedicina de la Universitat de Barcelona (IBUB), Universitat de Barcelona, E-08028 Barcelona, Spain

${ }^{2}$ CIBER Fisiopatología de la Obesidad y la Nutrición (CIBEROBN), Instituto de Salud Carlos III, Madrid, Spain

${ }^{3}$ Endocrinology and Diabetes Unit. Joan XXIII University Hospital, IISPV, Universitat Rovira i Virgili, E-43007 Tarragona, Spain.

${ }^{4}$ CIBER de Diabetes y Enfermedades Metabólicas Asociadas (CIBERDEM), Instituto de Salud Carlos III, Madrid, Spain

${ }^{5}$ Instituto de Investigaciones Biomédicas Alberto Sols, Consejo Superior de Investigaciones Científicas and Universidad Autónoma de Madrid (CSIC-UAM), E28029 Madrid, Spain

${ }^{6}$ Pharmacology Unit, Department of Pharmacology and Therapeutic Chemistry and IBUB, Faculty of Pharmacy, University of Barcelona, Barcelona, Spain

${ }^{7}$ Basic Sciences Department, Faculty of Medicine and Health Sciences, Universitat Internacional de Catalunya, E-08195 Sant Cugat del Vallés, Barcelona, Spain 


\section{Address correspondence to:}

27 Laura Herrero, $\mathrm{PhD}$

28 Department of Biochemistry and Molecular Biology, IBUB

29 School of Pharmacy

30 University of Barcelona

31 Av. Diagonal, 643

32 E-08028 Barcelona, Spain

33 Tel: (+34) 934024522

34 Fax: (+34) 934024520

35 Email: 1herrero@ub.edu

36

$37 \quad$ Running head

38 Fatty acid oxidation in adipocytes and macrophages

39

\section{Conflict of interest statement}

41 All authors declare no conflict of interest to disclose.

42

43 


\section{ABSTRACT}

45 Lipid overload in obesity and type 2 diabetes is associated with adipocyte dysfunction, 46 inflammation, macrophage infiltration and decreased fatty acid oxidation (FAO). Here

47 we report that the expression of carnitine palmitoyltransferase 1A (CPT1A), the rate-

48 limiting enzyme in mitochondrial FAO, is higher in human adipose tissue macrophages

49 than in adipocytes and that it is differentially expressed in visceral vs. subcutaneous

50 adipose tissue both in an obese and a type 2 diabetes cohort. These observations led us

51 to further investigate the potential role of CPT1A in adipocytes and macrophages. We

52 expressed CPT1AM, a permanently active mutant form of CPT1A, in 3T3-L1 CAR $\Delta 1$

53 adipocytes and RAW 264.7 macrophages through adenoviral infection. Enhanced FAO

54 in palmitate-incubated adipocytes and macrophages reduced triglyceride content and 55 inflammation, improved insulin sensitivity in adipocytes and reduced ER stress and 56 ROS damage in macrophages. We conclude that increasing FAO in adipocytes and 57 macrophages improves palmitate-induced derangements. This indicates that enhancing

58 FAO in metabolically relevant cells such as adipocytes and macrophages may be a 59 promising strategy for the treatment of chronic inflammatory pathologies such as 60 obesity and type 2 diabetes.

61 


\section{Keywords}

63 Obesity, type 2 diabetes, adipocytes, macrophages, inflammation, fatty acid oxidation, 64 CPT1.

65

\section{Abbreviations}

67 Ad, adenovirus; AGPAT5, 1-acylglycerol-3-phosphate O-acyltransferase 5; BCL2, B68 cell CLL/lymphoma 2; CD163, macrophage and monocyte marker; CHOP, C/EBP 69 homologous protein; CPT1A, carnitine palmitoyltransferase 1A; CPT1AM, carnitine 70 palmitoyltransferase 1A (permanently active mutant form); EDEM, ER degradation 71 enhancing $\alpha$-mannosidase-like protein; ER, endoplasmic reticulum; FA, fatty acids; 72 FAO, fatty acid oxidation; GFP, green fluorescent protein; IL-1 $\beta$, interleukin-1 $\beta$; IL-6, 73 interleukin-6; IRbeta, insulin receptor beta; MCP-1, monocyte chemoattractant protein74 1; moi, multiplicity of infection; PDI, protein disulfide isomerase; ROS, reactive 75 oxygen species; SAT, subcutaneous adipose tissue; SREBF1, Sterol regulatory element 76 binding transcription factor 1; SVF, stromal-vascular fraction; TLR-4, toll-like receptor77 4; VAT, visceral adipose tissue; WAT, white adipose tissue. 


\section{INTRODUCTION}

83 Obesity has reached epidemic proportions worldwide, leading to severe 84 associated pathologies such as insulin resistance, type 2 diabetes (T2D), cardiovascular 85 disease, Alzheimer's disease, hypertension, hypercholesterolemia, hypertriglyceridemia, 86 non-alcoholic fatty liver disease (NAFLD), arthritis, asthma, and certain forms of 87 cancer (12).

88 Over the last two decades adipose tissue has gained crucial importance in the 89 mechanisms involved in obesity-related disorders. The energy-storing white adipose 90 tissue (WAT) is well vascularized and contains adipocytes, connective tissue and 91 numerous immune cells such as macrophages, T and B cells, mast cells and neutrophils 92 that infiltrate and increase their presence during obesity (22). Macrophages were the 93 first immune cells reported to participate in obesity-induced insulin resistance (56). This 94 highlights their pathological role in adipose tissue in addition to their traditional 95 involvement in tissue repair and in response to dead and dying adipocytes $(5,14)$. Fat is 96 an active endocrine tissue that secretes hormones such as leptin, adiponectin or resistin 97 and inflammatory cytokines such as TNF- $\alpha$, IL-6, IL-1 $\beta$, etc. in response to several 98 stimuli. It is therefore a complex organ controlling energy expenditure, appetite, insulin 99 sensitivity, endocrine and reproductive functions, inflammation and immunity (53).

100 The pathophysiology of obesity-induced insulin resistance has been attributed to 101 ectopic fat deposition (39), increased inflammation and ER stress (16, 42), adipose 102 tissue hypoxia (15) and mitochondrial dysfunction (32), and impaired adipocyte 103 expansion and angiogenesis $(50,51,54)$. In obesity, fatty acids (FA) together with other 104 stimuli such as ceramide, various PKC isoforms, proinflammatory cytokines and ROS 105 and ER stresses activate JNK, NF- $\mathrm{BB}, \mathrm{RAGE}$ and TLR pathways both in adipocytes and 106 macrophages triggering inflammation and insulin resistance (43). 
107 Strenuous efforts are being made by the research community to elucidate the 108 mechanisms involved in the pathophysiology of obesity-related disorders. However, an 109 alternative strategy could be to act upstream by preventing the accumulation of lipids 110 and the progression of obesity. In addition to reducing caloric intake, a potential

111 effective approach to combat obesity would be to increase energy expenditure in key 112 metabolic organs, such as adipose tissue. Obese individuals and those with T2D are 113 known to have lower fatty acid oxidation (FAO) rates and lower electron transport chain 114 activity in muscle $(17,19,37)$ together with higher glycolytic capacities and enhanced 115 cellular FA uptake compared to non-obese and non-diabetic individuals (44). Thus, any 116 strategy able to eliminate the excess of lipids found in obesity could be beneficial for 117 health. Lipid levels can be reduced by inhibiting synthesis, transport or by increasing 118 oxidation: here we focus on the latter.

119 Malonyl-CoA, derived from glucose metabolism and the first intermediate in 120 lipogenesis, regulates FAO by inhibiting carnitine palmitoyltransferase 1 (CPT1). This 121 makes CPT1 the rate-limiting step in mitochondrial FA $\beta$-oxidation. Thus, in high122 energy conditions malonyl-CoA inhibits oxidation diverting FAs fate into TG 123 accumulation. There are three CPT1 isoforms, with differential tissue expression: 124 CPT1A (liver, kidney, intestine, pancreas, ovary and mouse and human WAT), CPT1B 125 (brown adipose tissue, skeletal muscle, heart and rat and human WAT), and CPT1C 126 (brain and testis) $(2,36)$. The fact that CPT1 controls FAO makes it a very attractive 127 target to reduce lipid levels and fight against obesity and T2D. In spite of their excess 128 fat, obese individuals have reduced visceral WAT CPT1 mRNA and protein levels (20). 129 This prompted our group and others to overexpress CPT1 in liver $(26,30,46)$, muscle $130(4,33,41)$, and white adipocytes (9), which led to a decrease in TG content and an 131 improvement in insulin sensitivity. 
132 Here we showed that CPT1A expression was higher in human adipose tissue 133 macrophages than in mature adipocytes and that it was differentially expressed in 134 visceral vs. subcutaneous adipose tissue. To further investigate the role of CPT1A in 135 both adipocytes and macrophages we used a permanently active mutant form of 136 CPT1A, CPT1AM, which is insensitive to its inhibitor malonyl-CoA (27), to achieve 137 continuous oxidation of lipids. When cells were incubated with palmitate to mimic 138 obesity, CPT1AM restored most of the palmitate-induced imbalances. An increase in 139 FAO in adipocytes and macrophages reduced TG content and inflammatory levels, 140 improved insulin sensitivity in adipocytes, and reduced endoplasmic reticulum (ER) 141 stress and ROS damage in macrophages.

142 


\section{MATERIALS AND METHODS}

\section{Human cohorts}

\section{Selection of patients}

146 Adipose tissue was selected from an adipose tissue biobank collection of the University

147 Hospital Joan XXII (Tarragona, Spain). All subjects were of Caucasian origin and

148 reported that their body weight had been stable for at least 3 months before the study.

149 They had no systemic disease other than obesity or T2D, and all had been free of any

150 infections in the previous month before the study. Liver and renal diseases were

151 specifically excluded by biochemical work-up. Appropriate Institutional Review Board

152 approval and adequate biobank informed consent was obtained from all participants.

153 Bio-banking samples included plasma, total and fractionated adipose tissue from

154 subcutaneous and visceral origin. All patients had fasted overnight before collection of

155 blood and adipose tissue samples. Visceral adipose tissue (VAT) and subcutaneous

156 adipose tissue (SAT) samples were obtained during surgical procedures that included

157 laparoscopic surgery for hiatus hernia repair or cholecystectomy. Samples were selected

158 according stratification by age, gender and BMI and grouped into two cohorts:

159 Obesity cohort. Subjects were classified by BMI according to the World Health

160 Organization criteria (WHO, 2000). The study included 19 lean, 28 overweight, and 15

161 obese non-diabetic subjects, matched for age and gender (Table 1).

162 Type 2 diabetes cohort. Patients were classified as having T2D according to the

163 American Diabetes Association criteria (1997). Variability in metabolic control was

164 assessed by stable glycated hemoglobin A1c (HbA1c) values during the previous 6

165 months. Gathering these criteria, there were 11 T2D subjects. As a control group, we

166 selected 36 subjects without diabetes from the obesity cohort, matched for age, BMI and

167 gender (Table 2). No patient was being treated with thiazolidinedione. 
169 Anthropometric measurements

170 Height was measured to the nearest $0.5 \mathrm{~cm}$ and body weight to the nearest $0.1 \mathrm{~kg}$. BMI

171 was calculated as weight (kilograms) divided by height (meters) squared. Waist

172 circumference was measured midway between the lowest rib margin and the iliac crest. 173

174 Collection and processing of human samples

175 Samples from VAT (visceral adipose tissue, omental) and SAT (subcutaneous adipose 176 tissue, anterior abdominal wall) from the same individual were obtained during 177 abdominal elective surgical procedures (cholecystectomy or surgery for abdominal 178 hernia). All patients had fasted overnight, at least 12 hours before surgical procedure. 179 Blood samples were collected before the surgical procedure from the antecubital vein, $18020 \mathrm{ml}$ of blood with EDTA $(1 \mathrm{mg} / \mathrm{ml})$ and $10 \mathrm{ml}$ of blood in silicone tubes. $15 \mathrm{ml}$ of 181 collected blood was used for the separation of plasma. Plasma samples were stored at $18280^{\circ} \mathrm{C}$ until analytical measurements were performed. $5 \mathrm{ml}$ of blood with EDTA was 183 used for the determination of $\mathrm{HbA1c}$. Adipose tissue samples were collected, washed in 184 PBS, immediately frozen in liquid $\mathrm{N}_{2}$ and stored at $-80^{\circ} \mathrm{C}$.

185

186 Adipose tissue fractionation

187 Adipose tissue biopsies were immediately processed. The adipose tissue was finely 188 diced into small pieces (10-30 mg), washed in PBS and incubated in Medium 199 (Life 189 Technologies) supplemented with $4 \%$ BSA plus $2 \mathrm{mg} / \mathrm{ml}$ of collagenase Type I (Sigma) 190 for $1 \mathrm{~h}$ in a shaking water bath at $37^{\circ} \mathrm{C}$. After digestion, mature adipocytes (ADI) were 191 separated from tissue matrix by filtration through a $200 \mu \mathrm{m}$ mesh fabric (Spectrum 192 Laboratories). The filtrated solution was centrifuged for $5 \mathrm{~min}$ at $1500 \mathrm{xg}$. The mature 
193 adipocytes were removed from the top layer and the SVF cells remained in the pellet.

194 Cells were washed 4 times in PBS and processed for RNA and protein extraction.

195

196 Analytical methods

197 Glucose, cholesterol and TG plasma levels were determined in an auto-analyser

198 (Hitachi 737, Boehringer Mannheim) using the standard enzyme methods. High-density

199 lipoprotein (HDL) cholesterol was quantified after precipitation with polyethylene

200 glycol at room temperature (PEG-6000). Plasma insulin was determined by

201 radioimmunoassay (Coat-A-Count insulin; Diagnostic Products Corp.). Non-esterified

202 Free Fat Acid (NEFA) serum levels were determined in an autoanalyser (Advia 1200,

203 Siemens AG) using an enzymatic method developed by Wako Chemicals. Plasma

204 glycerol levels were analyzed by using a free glycerol determination kit, a quantitative

205 enzymatic determination assay (Sigma-Aldrich Corp.). Intra- and interassay CV were

206 less than $6 \%$ and less than $9.1 \%$, respectively. The degree of insulin resistance was

207 determined by the homeostasis model assessment (HOMA), as [glucose (mmol/l) x 208 insulin $(\mathrm{mIU} / \mathrm{l})] / 22.5](24)$.

209

210 Immunohistochemistry

211 Five-micron sections of formalin-fixed paraffin-embedded adipose tissue were

212 deparaffinised and rehydrated prior to antigen unmasking by boiling in 1mM EDTA,

$213 \mathrm{pH}$ 8. Sections were blocked in normal serum and incubated overnight with rabbit anti-

214 CPT1A (Sigma-Aldrich) at 1:50 dilution. Secondary antibody staining was performed

215 using the VECTASTAIN ABC kit (Vector Laboratories, Inc.) and detected with

216 diaminobenzidine (DAB, Vector Laboratories, Inc.). Sections were counterstained with

217 hematoxylin prior to dehydration and coverslip placement, and examined under a Nikon 
218 Eclipse 90i microscope. As a negative control, the procedure was performed in the 219 absence of primary antibody.

220

221

Immunofluorescence

222 Five-micron sections of formalin-fixed paraffin-embedded adipose tissue were blocked 223 in normal serum and incubated overnight with rabbit anti-CPT1A antibody (Sigma224 Aldrich) at 1:50 dilution, and with mouse anti-CD68 (Santa Cruz Biotechnology, Inc.) 225 at 1:50 dilution, washed, and visualized using Alexa Fluor 546 goat anti-rabbit, and 226 Alexa Fluor 488 goat anti-mouse antibodies, respectively (1:500; Molecular Probes 227 Inc.). The slides were counterstained with DAPI (4,6-diamidino-2-phenylindole) to 228 reveal nuclei and were examined under a Nikon Eclipse 90i fluorescent microscope. As 229 a negative control, the assay was performed in the absence of primary antibody.

\section{$231 \quad$ Materials}

232 Sodium palmitate, sodium oleate, BSA and L-carnitine hydrochloride were purchased 233 from Sigma Aldrich. DMEM, FBS and Penicillin/Streptomycin mixture were purchased 234 from Life Technologies.

235

\section{Cell culture}

237 Murine 3T3-L1 CAR $\Delta 1$ preadipocytes, kindly given by Dr. Orlicky (Department of 238 Pathology, UCHSC at Fitzsimons, Aurora, CO, USA), were cultured and differentiated 239 into mature adipocytes following the published protocol (31). Mature adipocytes were 240 used for experiments at day 8 post-differentiation. Murine RAW 264.7 macrophages 241 were obtained from ATCC and were maintained in DMEM supplemented with 10\% 242 heat-inactivated FBS and 1\% penicillin/streptomycin mixture. Simpson-Golabi-Behmel 
243 Syndrome (SGBS) human cells were cultured and differentiated to adipocytes as 244 previously described (55).

245

246 Adenovirus (Ad) infection

247 At day 8 of differentiation, 3T3-L1 CAR $\Delta 1$ cells were infected with AdGFP (100 moi) 248 and AdCPT1AM (13) (100 moi) for $24 \mathrm{~h}$ in serum-free DMEM and then the medium 249 was replaced with complete DMEM for additional $24 \mathrm{~h}$. RAW 264.7 macrophages were 250 infected with AdGFP (100 moi) and AdCPT1AM (100 moi) for $2 \mathrm{~h}$ in serum-free 251 DMEM and then replaced with complete medium for additional $72 \mathrm{~h}$. The adenovirus 252 infection efficiency was assessed in AdGFP-infected cells (Figure 3A and B). The same 253 batch of adenoviruses stored in $50 \mu 1$ aliquots was used throughout the experiments.

255 Fatty acid (FA) treatment

256 Sodium palmitate was conjugated with FA-free BSA in a 5:1 ratio to yield a stock 257 solution of $2.5 \mathrm{mM}$ (41). Cells were incubated with $0.3 \mathrm{mM}$ or $1 \mathrm{mM}$ of this solution for $25824 \mathrm{~h}$ (3T3-L1 CAR $\Delta 1$ adipocytes) or $0.3 \mathrm{mM}, 0.5 \mathrm{mM}$ or $0.75 \mathrm{mM}$ for 24,8 or $18 \mathrm{~h}$ 259 (RAW 264.7 macrophages), respectively.

260

261 Adipocyte and macrophage viability

262 3T3-L1 CAR $\Delta 1$ adipocytes and RAW 264.7 macrophages were infected as previously 263 described and incubated for $24 \mathrm{~h}$ with $1 \mathrm{mM}$ or $0.3 \mathrm{mM}$ palmitate, respectively. Cells 264 were washed twice with PBS and lifted from the surface with trypsin followed by 2 min 265 incubation at $37^{\circ} \mathrm{C}$. Trypsinization was stopped with $10 \%$ FBS containing media and 266 equal volumes of cell suspension were mixed with $0.4 \%$ Trypan blue staining. Trypan 267 blue positive and negative cells were counted using a Neubauer chamber for adipocytes 
268 and Countess Automated Cell Counter (Invitrogen) for macrophages. Percentage of

269 viability was determined normalizing viable cells of each group to viable cells of BSA

270 GFP group. Statistical significance was assessed using two-way Anova analysis of three

271 individual experiments $(* \mathrm{p}<0.05)$.

272

273 CPT1 activity

274 Mitochondria-enriched fractions were obtained from cell culture grown in $10-\mathrm{cm}^{2}$ 275 dishes and CPT1 activity was measured by a radiometric method as described (13).

276

277 Fatty acid oxidation

278 Total oleate oxidation was measured in 3T3-L1 CAR $\Delta 1$ adipocytes and RAW 264.7 279 macrophages grown in $25-\mathrm{cm}^{2}$ flasks, differentiated, and infected as described above. 280 The day of the assay cells were washed in $\mathrm{KRBH} 0.1 \%$ BSA, preincubated at $37^{\circ} \mathrm{C}$ for 28130 min in $\mathrm{KRBH} 1 \% \mathrm{BSA}$, and washed again in $\mathrm{KRBH} 0.1 \%$ BSA. Cells were then 282 incubated for $3 \mathrm{~h}$ (3T3-L1 CAR $\Delta 1$ adipocytes) or $2 \mathrm{~h}$ (RAW 264.7 macrophages) at $28337^{\circ} \mathrm{C}$ with fresh $\mathrm{KRBH}$ containing $11 \mathrm{mM}$ glucose, $0.8 \mathrm{mM}$ carnitine plus $0.2 \mathrm{mM}$ [1-

$\left.284{ }^{14} \mathrm{C}\right]$ oleate (Perkin Elmer). Oxidation was measured as described (30). The scintillation 285 values were normalized to the protein content of each flask.

286

287

TG content

288 Cells were grown in 12-well plates, differentiated and infected as described above. 289 After 24 h (3T3-L1 CAR 1 adipocytes) or 18 h (RAW 264.7 macrophages) of FA 290 treatment, cells were collected for lipid extraction following Gesta et al protocol (10) 291 with minor modifications: after cell lysis with $0.1 \%$ SDS, 1/2/0.12 (v/v/v) 292 methanol/chloroform/0.5M KCl solution was added, the two phases were separated by 
293 centrifugation and the upper phase was dried with $\mathrm{N}_{2}$. Finally, lipids were resuspended 294 in 100\% isopropanol and TG were quantified using TG Triglyceride kit (Sigma), 295 according to the manufacturer's instructions. Protein concentrations were used to 296 normalize sample values.

297

298 Oil Red O staining

299 RAW 264.7 macrophages grown on coverslips were infected as described above and 300 incubated with $0.75 \mathrm{mM}$ of palmitate for 18 hours. After this time, cells were rinsed 301 twice with PBS, fixed in 10\% paraformaldehyde for 30 minutes at room temperature 302 and washed again with PBS. Then, cells were rinsed with 60\% isopropanol for 5 min to 303 facilitate the staining of neutral lipids and stained with filtered Oil Red $\mathrm{O}$ working 304 solution (0.3\% Oil Red O in isopropanol) for $15 \mathrm{~min}$. After several washes with 305 distilled water the coverslips were removed and mounted on a drop of mount medium.

306 The intracellular lipid vesicles stained with Oil Red O were identified by their bright red 307 color under the microscope.

308

309 Analysis of intracellular protein oxidation

310 RAW 264.7 macrophages were cultured in 12-well plates and infected as described 311 before. After FA treatment, cell extracts were prepared and analyzed for protein 312 oxidative modifications (i.e. carbonyl group content) with OxyBlot Protein Oxidation 313 Detection kit (Millipore), following the manufacturer's instructions.

315 Western blot analysis

316 3T3-L1 CARA1 adipocytes and RAW 264.7 macrophages were cultured in 12-well 317 plates, differentiated, and infected as described above. Cells were collected in lysis 
318 buffer (RIPA) and protein concentration was determined using the BCA protein assay

319 kit (Thermoscientific). Equal amount of protein from whole cell lysates was resolved by $3208 \%$ SDS-PAGE and transferred to PVDF membranes (Millipore). Signal detection was

321 carried out with the ECL immunoblotting detection system (GE Healthcare) and the 322 results were quantitatively analyzed using Image Quant LAS4000 Mini (GE 323 Healthcare). The following antibodies were used: CPT1A (1/6,000; (13)), $\beta$-actin (I-19) 324 (1/4,000; Santa Cruz), Akt and pAkt $\left(\operatorname{Ser}^{473}\right)(1 / 1,000$; Cell Signaling), CHOP (GADD 325 153; 1/200; Santa Cruz) and IRbeta (1/1,000; Santa Cruz). Human fat tissue was 326 homogenized in RIPA buffer as previously described (34). Protein extracts (10-20 $\mu \mathrm{g})$ 327 were loaded, resolved on $10 \%$ SDS-PAGE and transferred to Hybond ECL 328 nitrocellulose membranes. Membranes were stained with $0.15 \%$ Ponceau red (Sigma329 Aldrich) to ensure equal loading after transfer and then blocked with 5\% (w/v) BSA in 330 TBS buffer with $0.1 \%$ Tween 20 . Immunoblotting was performed with 1:2000 goat 331 anti-human CPT1A (Abcam). Blots were incubated with the appropriate IgG-HRP332 conjugated secondary antibody. Immunoreactive bands were visualized with an ECL333 plus reagent kit (GE Healthcare). Optical densities of the immunoreactive bands were 334 measured using Image $\mathrm{J}$ analysis software.

336 Analysis of mRNA expression by quantitative real-time PCR

337 Total RNA was extracted from cultured cells grown in 12-well plates using Illustra 338 MiniRNA Spin kit (GE Healthcare) and cDNA was obtained using Transcriptor First 339 Strand cDNA Synthesis kit (Roche). Quantitative real-time PCR was performed using 340 SYBR Green PCR Master Mix Reagent Kit (Life Technologies). Levels of mRNA were 341 normalized to those of $\beta$-actin and expressed as fold change. Forward/reverse primers 342 for several used genes (other sequences are available upon request): 


\begin{tabular}{|c|c|c|}
\hline & FORWARD & REVERSE \\
\hline$\beta$-ACTIN & 5'- AGGTGACAGCATTGCTTCTG- 3' & 5'- GCTGCCTCAACACCTCAAC-3' \\
\hline $\mathrm{CHOP}$ & 5'-CCCTGCCTTTCACCTTGG- 3' & 5'-CCGCTCGTTCTCCTGCTC- 3' \\
\hline CPT1A* & 5'- GCAGCAGATGCAGCAGATCC- 3' & 5'-TCAGGATCCTCCTCTCTGTATCCC3' \\
\hline EDEM & 5'-AAGCCCTCTGGAACTTGCG- 3' & 5'-AACCCAATGGCCTGTCTGG- 3' \\
\hline GRP78 & 5'-ACTTGGGGACCACCTATTCCT- 3' & 5'-ATCGCCAATCAGACGCTCC- 3' \\
\hline IL-1 $\beta$ & 5'- GCCCATCCTCTGTGACTCAT- 3' & 5'- AGGCCACAGGTATTTTGTCG- 3' \\
\hline MCP-1 & 5'- TCCCAATGAGTAGGCTGGAG-3' & 5'- AAGTGCTTGAGGTGGTTGTG- 3' \\
\hline PDI & 5'-ACCTGCTGGTGGAGTTCTATG- 3' & 5'-CGGCAGCTTTGGCATACT- 3' \\
\hline TLR-4 & 5'- GGACTCTGATCATGGCACTG- 3' & 5'- CTGATCCATGCATTGGTAGGT- 3' \\
\hline TNF- $\alpha$ & 5'-ACGGCATGGATCTCAAAAGAC-3' & 5'-AGATAGCAAATCGGCTGAACG- 3' \\
\hline
\end{tabular}

* Recognizes both CPT1A and CPT1AM

400-500mg frozen human adipose tissue was homogenized with an Ultra-Turrax

3468 (Ika). Total RNA from adipose biopsies, stromal-vascular fractions (SVF) and isolated

347 adipocytes were extracted by using RNeasy Lipid Tissue Midi Kit (QIAGEN Science)

348 following the manufacturer's instructions and total RNA was treated with 55 U RNase-

349 free DNase (QIAGEN) to avoid contamination with genomic DNA. Between 0.2 and 1

$350 \mu \mathrm{g}$ of total RNA was reverse-transcribed to cDNA using TaqMan Reverse Transcription

351 reagents (Applied Biosystems), and subsequently diluted with nuclease-free water

352 (Sigma) to $20 \mathrm{ng} / \mu \mathrm{l} \mathrm{cDNA}$. For adipose tissue gene expression analysis a real-time

353 quantitative PCR was performed, with duplicates, on a 7900HT Fast Real-Time PCR

354 System using commercial Taqman Assays (Applied Biosystems). SDS software 2.3 and

355 RQ Manager 1.2 (Applied Biosystems) were used to analyse the results with the 356 comparative threshold cycle $(\mathrm{Ct})$ method $\left(2^{\Delta \Delta \mathrm{Ct}}\right)$. $\mathrm{C}_{\mathrm{t}}$ values for each sample were 357 normalized with an optimal reference gene (cyclophilin), after testing three additional 
358 housekeeping genes: $\beta$-actin and RNA 18S. A panel of genes involved in the adipocyte

359 differentiation and metabolism was selected in the study of CPT1A gene expression:

\begin{tabular}{|c|c|c|}
\hline GEN SIMBOL & GENE DENOMINATION & ASSAI ID \\
\hline ACC1 & (acetyl-coenzyme carboxylase 1) ACACA & Hs00167385_m1 \\
\hline PCK2 & (phosphoenolpyruvate carboxykinase 2) & Hs00388934_m1 \\
\hline $\operatorname{PPAR} \alpha$ & (peroxisome proliferator-activated receptor $\alpha$ ) & Hs00231882_m1 \\
\hline $\operatorname{PPAR} \gamma$ & (peroxisome proliferator-activated receptor $\lambda$ ) & Hs00234592_m1 \\
\hline AGPAT3 & $\begin{array}{l}\text { (1-acyl-sn-glycerol-3-phosphate acyltransferase gamma / } \\
\text { LPAAT-g1) }\end{array}$ & Hs00987571_m1 \\
\hline AGPAT4 & $\begin{array}{l}\text { (1-acyl-sn-glycerol-3-phosphate acyltransferase / LPAAT- } \\
\text { d) }\end{array}$ & Hs00220031_m1 \\
\hline AGPAT5 & $\begin{array}{l}\text { (1-acyl-sn-glycerol-3-phosphate acyltransferase / LPAAT- } \\
\text { e) }\end{array}$ & Hs00218010_m1 \\
\hline AGPAT9 & $\begin{array}{l}\text { (1-acylglycerol-3-phosphate 0-acyltransferase 9/ LPAAT- } \\
\text { theta) }\end{array}$ & Hs00262010_m1 \\
\hline CDS1 & (phosphatidate cytidylyltransferase) & Hs00181633_m1 \\
\hline PCYT1A & (choline-phosphate cytidylyltransferase) & Hs00192339_m1 \\
\hline PCYT2 & (ethanolamine-phosphate cytidylyltransferase & Hs00161098_m1 \\
\hline PDE3B & (phosphodiesterase type 3) & Hs01057215_m1 \\
\hline FDFT1 & (farnesyl-diphosphate farnesyltransferase 1) & Hs00926054_m1 \\
\hline SREBF1 & (sterol regulatory element binding transcription factor 1 ) & Hs01088691_m1 \\
\hline BCL2 & (B-cell CLL/lymphoma 2) & Hs99999018_m1 \\
\hline CD163 & Macrophage and monocyte marker & Hs01016661_m1 \\
\hline CPT1A & (carnitine palmitoyltransferase $1 \mathrm{~A}$ ) & Hs00912676_m1 \\
\hline
\end{tabular}

360

361 Cytokines measurement in culture media

362 Cytokines protein levels in culture media of 3T3-L1 CAR $\Delta 1$ adipocytes and RAW

363264.7 macrophages were measured by Luminex technology with a MILLIPLEX

364 Analyzer Luminex 200x Ponenet System (MCYTOMAG-70K-08 Mouse Cytokine

365 MAGNETIC Kit; Merck Millipore).

366 
368 Analysis of cellular redox status

369 To detect ROS (superoxide) formation, MitoSOX Red (M36008 - Life Techonologies)

370 fluorescence was measured by flow cytometry. RAW 264 cells were infected with 100

371 moi AdCPT1AM (or AdGFP as control) for 48h; then 16h prior to ROS measurement,

372 macrophages were treated with $0.75 \mathrm{mM}$ palmitate BSA-conjugated (or with BSA as

373 control). Medium was removed and cells were incubated for 30 min with PBS

374 containing $5 \mu \mathrm{M}$ MitoSOX Red. The labeled macrophages were washed three times 375 with $\mathrm{HBSS} / \mathrm{Ca} / \mathrm{Mg}$, pelleted, resuspended in $300 \mu \mathrm{HBSS} / \mathrm{Ca} / \mathrm{Mg}$ and fixed by adding

$3761.2 \mathrm{ml}$ absolute ethanol and keeping them at $-20^{\circ} \mathrm{C}$ for 5 minutes. Cells were pelleted 377 again and resuspended in $\mathrm{HBSS} / \mathrm{Ca} / \mathrm{Mg}$ containing $3 \mu \mathrm{M}$ DAPI, to mark their nuclei. 378 Then macrophages were analyzed by flow cytometry (Gallios Cytometer - Beckman 379 Coulter). The fluorescence intensity of MitoSOX Red was measured using excitation at $380510 \mathrm{~nm}$ and emission at $580 \mathrm{~nm}$.

381

\section{$382 \quad$ Statistical analysis}

383 Data are expressed as the mean \pm SEM and analyzed statistically using Student's $t$-test 384 (column analysis) or two-way ANOVA (grouped analysis). All figures and statistical 385 analyses were generated using GraphPad Prism 6. $P<0.05$ was considered statistically 386 significant. For human data statistical analyses were performed with SPSS 12.0 (SPSS). 387 Results are expressed as mean $\pm \mathrm{SD}$. The non-normally distributed variables were 388 represented as the median (interquartile range). Categorical variables were reported by 389 number (percentages). Student's t test analysis was used to compare the mean value of 390 normally distributed continuous variables. Variables with a non-Gaussian distribution 391 were analyzed by using non-parametric test (Kruskal-Wallis, or Mann-Whitney test for 
392 independent samples or Wilcoxon test for related samples when necessary).

393 Associations between continuous variables are sought by correlation analyses. Finally a 394 stepwise multiple linear regression analysis is performed to determine independent 395 variables associated with CPT1A gene expression levels in SAT and VAT depot. 396 Results are expressed as unstandardized coefficient (B), and 95\% confidence interval 397 for B (95\%CI(B)). Differences are considered significant if a computed two-tailed 398 probability value $(\mathrm{P})$ is $<0.05$.

399

400 


\section{RESULTS}

402 CPT1A expression pattern in human adipose tissue from obese and diabetic 403 patients

404 Visceral and subcutaneous adipose tissue (VAT and SAT, respectively) were 405 analyzed from both an obesity cohort (lean, overweight and obese patients) and a T2D 406 cohort (control and T2D patients). Tables 1 and 2 show the phenotypic and metabolic 407 characteristics and CPT1A expression levels of the subjects. No differences in CPT1A 408 gene expression levels either in SAT or in VAT depots were observed when comparing 409 with the non-obese or the non-diabetic counterparts (Fig. 1A and B; Tables 1 and 2). 410 However, in the obesity cohort, CPT1A mRNA expression was significantly higher in 411 lean and overweight VAT than in SAT (Fig. 1A). This difference was lost in the obese 412 patients. These results were corroborated by Western blot with human adipose tissue of 413 several lean and obese individuals (Fig. $1 \mathrm{C}$ and $\mathrm{D}, \mathrm{P}=0.015$ ). Similar results were 414 obtained in the T2D cohort, where control subjects showed significantly higher CPT1A 415 mRNA levels in VAT vs. SAT (Fig. 1B). However, this difference disappeared in T2D 416 patients. Despite T2D patients showed a trend to express higher CPT1A levels in SAT 417 and VAT compared to controls (on the opposite than in the obese subjects) this 418 difference was non-significant. Since CPT1B isoform is also expressed in human 419 adipose tissue we analyzed CPT1B mRNA (Fig. 1E and F) and protein (data not shown) 420 levels in human VAT and SAT of the obesity and the T2D cohort. No differences were 421 seen among the groups.

422 In order to establish the main relationship between CPT1A gene expression and 423 key adipocyte genes involved in differentiation and metabolic pathways we explored a 424 panel of genes (listed in Material and Methods) both in SAT and VAT depots of the 425 obesity cohort. Results are shown from those genes that changed the most (up or down) 
426 (Tables 3 and 4). Simple association analysis showed an inverse correlation between 427 CPT1A and PPAR- $\gamma$ in SAT $(r=-0.38, \mathrm{P}=0.002)$ (Table 3). Positive CPT1A correlation 428 both in VAT and SAT was found with AGPAT5 (phospholipid biosynthesis), SREBF1 429 (glucose and lipid metabolism), BCL2 (anti-apoptosis) and CD163 (macrophage 430 marker) (Table 3).

431 To study the main determinants of CPT1A gene expression levels, a stepwise 432 multiple regression analysis was performed, including the above-mentioned bivariate 433 associations and confounding factors such as BMI, age and gender. This model showed 434 that SAT CPT1A was positively associated with AGPAT5, SREBF1 and CD163 and 435 that VAT CPT1A was positively correlated with SREBF1 and CD163 and negatively 436 with age and PPAR- $\gamma$ (Table 4). The inverse relationship between CPT1A and PPAR- $\gamma$ 437 was corroborated with the human adipocyte cell line SGBS. CPT1A mRNA expression 438 dropped to a new steady state in adipocytes that was $11 \%$ of its expression in fibroblasts 439 (data not shown).

\section{CPT1A is highly expressed in human adipose tissue macrophages}

442 To determine the cellular distribution of CPT1A gene and protein in human 443 adipose tissue biopsies, we performed qRT-PCR and immunostaining analysis on both 444 adipose and stromal-vascular fraction (SVF). CPT1A mRNA levels were 42.6-, and 445 43.4-fold increased in the SVF compared to mature adipocytes in both human SAT $446(\mathrm{P}<0.05)$ and VAT $(\mathrm{P}<0.05)$, respectively (Fig. 2A). Immunohistological examination 447 of SAT from obese subjects revealed CPT1A+ cells mostly in the SVF (Fig. 2B). 448 Immunofluorescence detection showed a bright staining pattern in cells resembling 449 adipose tissue macrophages. Co-staining analysis using CPT1A and CD68 (a 450 macrophage marker) antibodies confirmed the expression of CPT1A in macrophages 
451 (Fig. 2C). Macrophages seem to localize forming the so-called "crown-like structures"

452 surrounding the adipocytes.

453

454

455

CPT1AM-expressing adipocytes show enhanced FAO and reduced TG content

To further study the role of CPT1A in adipocytes and macrophages we decided to continue with in vitro studies. Since 3T3-L1 adipocytes are inefficiently infected with

457 adenovirus we decided to use the high-infection efficiency white adipocyte cell culture 458 line, 3T3-L1 CAR $\Delta 1$ adipocytes (31) (Fig. 3A). Cells were transduced for the first time 459 with adenoviruses carrying the CPT1AM gene or GFP as a control. Interestingly, 460 CPT1AM-expressing adipocytes were partially protected from palmitate induced cell 461 death (Fig. 3C).

462 CPT1A mRNA, protein and activity levels were increased in CPT1AM463 expressing adipocytes compared to GFP control cells (Fig. 4A-C). CPT1AM-expressing 464 adipocytes retained most of the CPT1 activity after incubation with the CPT1A inhibitor 465 malonyl-CoA (Fig. 4C). FAO rate was concordantly enhanced (1.37-fold increase, $466 \mathrm{P}<0.05$ ) in CPT1AM-expressing adipocytes (Fig. 4D). FA undergoing $\beta$-oxidation yield 467 acetyl-CoA moieties that have two main possible fates: (1) complete oxidation to $\mathrm{CO}_{2}$ 468 and ATP production, or (2) conversion to ketone bodies (mainly in the liver). Here, total 469 FAO rate was calculated as the sum of acid soluble products plus $\mathrm{CO}_{2}$ oxidation. 470 CPT1AM expression blocked the palmitate-induced increase in TG content (Fig. 4E).

471

472 Enhanced adipocyte FAO improves insulin sensitivity and reduces inflammation

473 We examined the effect of increased FAO on insulin sensitivity and 474 inflammatory responses in $3 \mathrm{~T} 3-\mathrm{L} 1 \mathrm{CAR} \Delta 1$ adipocytes infected with AdCPT1AM. 475 Palmitate-induced decrease in insulin-stimulated Akt phosphorylation and insulin 
476 receptor beta (IRbeta) protein levels was partially restored in CPT1AM-expressing

477 adipocytes (Fig. 4F-H). Palmitate-induced increase of proinflammatory markers (IL-1 $\beta$,

478 MCP-1 and IL-1 $\alpha$ ) mRNA and protein levels was blunted in CPT1AM-expressing

479 adipocytes (Fig. 4I-K). Several palmitate concentrations and times of incubation were

480 used to better fit the different dose- and time-response of the cytokines and parameters

481 measured. Consistent with previous studies $(9,11)$, palmitate incubation raised 482 cytokines expression by 2-3-fold.

483

484

485

486

487

488

Increased FAO in CPT1AM-expressing macrophages protects from palmitateinduced TG accumulation

489 infected with AdCPT1AM (Fig. 3B). CPT1AM-expressing macrophages were protected

490 from palmitate induced cell death (Fig. 3D). CPT1AM-expressing macrophages showed 491 a 2.4-fold $(\mathrm{P}<0.01)$ increase in CPT1A mRNA levels, 6.6-fold $(\mathrm{P}<0.01)$ increase in 492 protein levels and 2.2-fold $(\mathrm{P}<0.05)$ increase in activity levels (Fig. 5A-C). In addition, 493 we showed that malonyl-CoA did not inhibit CPT1 activity in CPT1AM-expressing 494 macrophages (Fig. 5C). CPT1AM-expressing macrophages showed a 1.5-fold increase 495 in FAO rate compared to GFP control cells (Fig. 5D, P<0.05) and a total restoration in 496 palmitate-induced enhancement of TG content (Fig. 5E and F).

497

498 Enhanced macrophage FAO reduced inflammation, ER stress and ROS damage

499 Palmitate-induced increase in proinflammatory cytokines (TNF- $\alpha$, MCP-1, IL-

$5001 \beta$, TLR-4 and IL-12p40) and ER stress markers (CHOP, GRP78, PDI and EDEM) 
501 mRNA and protein levels was blunted in CPT1AM-expressing macrophages (Fig. 6A,

502 B, D and E)). Consistent with previous studies $(18,47,48)$, palmitate incubation raised

503 cytokines expression by 2-3-fold. No differences were seen in anti-inflammatory

504 markers such as IL-10, Mgl-1 and IL-4 in CPT1AM-expressing cells incubated with or

505 without palmitate (Fig. 6C). Incubation with etomoxir, a permanent inhibitor of CPT1A,

506 counteracted the reduction of MCP-1 expression seen in CPT1AM-expressing cells

507 incubated with palmitate (data not shown). We also studied the effect of enhanced FAO

508 in RAW 264.7 macrophages on palmitate-induced ROS damage by protein carbonyl

509 content analysis. Palmitate-induced ROS damage was reduced in CPT1AM-expressing

510 macrophages (Fig. 6F). This reduction was not detected when ROS (superoxide) was

511 directly measured by using the MitoSOX Red probe (Fig. 6G).

512 


\section{DISCUSSION}

514 The obesity epidemic has put a spotlight on the adipose tissue as a key player in 515 obesity-induced insulin resistance (38). Obese individuals and those with T2D have 516 lower FAO rates $(17,19,37)$. Although these data were reported in skeletal muscle, we 517 expected to see reduced CPT1A expression levels in the adipose tissue of both obese 518 and T2D patients. However, no differences were seen in CPT1A mRNA expression 519 between the obese or T2D and their respective controls either in VAT or in SAT. Other 520 authors have reported a decrease in VAT CPT1 mRNA and protein levels in obese 521 individuals (20). However, the authors did not specify which of the CPT1 isoforms was 522 measured in VAT: CPT1A or CPT1B. We showed that CPT1A expression is higher in 523 adipose tissue macrophages than in mature adipocytes. Since the obese adipose tissue 524 has higher infiltration of immune cells such as macrophages, we postulate that the 525 putative decrement of CPT1A expression in obese individuals could be compensated by 526 increased expression from the infiltrated macrophages and thus, no differences are seen 527 between the groups. CPT1B isoform is also expressed in human adipose tissue and it 528 has been shown to raise FAO in metabolic tissues such as skeletal muscle (3). Thus, we 529 measured mRNA and protein levels in the obese and T2D cohorts. However, no 530 differences were seen among the groups indicating that CPT1B expression is not 531 changed by obesity and T2D.

532 We found that in insulin sensitive individuals (control and overweight patients 533 from the obese cohort and control patients from the T2D cohort) CPT1A mRNA 534 expression was higher in VAT than in SAT. However, no differences between VAT and 535 SAT were seen in the more insulin-resistant individuals with a more pro-inflammatory 536 environment: obese and T2D patients. A similar phenomenon was described for $\mathrm{T}$ 537 regulatory cells, described to have anti-inflammatory properties and to improve obesity- 
538 induced insulin resistance (7). The authors reported that VAT and SAT of healthy

539 individuals had similar low numbers of $\mathrm{T}$ regulatory cells at birth, with a progressive

540 accumulation over time in the VAT, though not the SAT. Our results suggest a CPT1A

541 expression balance between SAT and VAT depots that may be disturbed in obese and

542 T2D patients. The difference in CPT1A expression between these two fat depots is

543 potentially crucial, given the association of VAT, but not SAT with insulin resistance

544 (1, 52). It might indicate, in healthy individuals, a potential protective role of CPT1A in 545 the more insulin-resistant associated VAT.

546 Gene expression analysis revealed a negative association between CPT1A and 547 the adipocyte marker of differentiation PPAR- $\gamma$. This is consistent with the fact that

548 while white adipocytes mature they shift their lipid preferences to storage rather than

549 oxidation. Aging was associated with reduced CPT1A expression in VAT. This might

550 reflect a potential protective role of CPT1A expression in VAT, which is lost with age.

551 Considering that VAT accretion is a hallmark of aging and especially, it is a stronger

552 risk factor for comorbidities and mortality (23), we speculate a favorable role of

553 enhanced CPT1A expression in age metabolic decline and related pathological

554 conditions. Positive correlation both in VAT and SAT CPT1A was found with

555 AGPAT5, SREBF1, BCL2 and CD163. These results may indicate a potential role of

556 CPT1A in lipid biosynthesis processes (AGPAT5), glucose and lipid metabolism

557 (SREBF1) and in protecting adipose tissue from apoptosis (BCL2). The positive 558 association between CPT1A and CD163 (macrophage marker) was not surprising given 559 the higher CPT1A expression in macrophages than in adipocytes (Fig. 2).

560 We are aware that many of the above mentioned associations may be secondary

561 to obesity or T2D and that no causal relationship may be inferred with this study design.

562 In order to prove the causality of some of these observations we performed in vitro 
563 studies directly targeting adipocytes and macrophages to burn off the excess lipids

564 through an increase in FAO. We used the high-infection efficiency adipocyte cell line,

565 3T3-L1 CAR $\Delta 1$ (31), to express for the first time CPT1AM through adenoviral

566 infection. Noteworthy, white adipocytes are designed to store lipids rather than to

567 oxidize them. Thus, CPT1 activity in WAT is lower than in other tissues (6). However,

568 CPT1AM-expressing adipocytes showed a 4.3-fold increase in CPT1 activity that was

569 not inhibited despite incubation with high concentrations of malonyl-CoA. Since

570 increased lipid accumulation, inflammation, ER stress and ROS-induced protein

571 damage trigger metabolic diseases we decided to measure TG content, inflammation,

572 ER stress and ROS damage as important mechanisms that could explain the potential

573 protective effect of CPT1AM expression. Enhanced FAO led to complete restoration of

574 TG content, improved insulin signaling (measured as pAkt), increased IRbeta

575 expression and cell viability and reduced inflammation in palmitate-incubated

576 CPT1AM-expressing adipocytes. CPT1AM-expressing adipocytes showed a general

577 improvement in lipid-induced derangements as a consequence of increased FA flux

578 through mitochondria. However, enhanced FA flux in the absence of a concomitant

579 dissipation of FAO metabolites has been associated with increased ROS damage (35)

580 and inflammation $(8,21,43)$. Interestingly, while no differences were seen in ER or

581 oxidative stress (data not shown), CPT1AM-expressing adipocytes showed a significant

582 decrease in proinflammatory mediators such as IL-1 $\beta$ and MCP-1. The favorable role of

583 CPT1A in adipocytes to attenuate FA evoked insulin resistance and inflammation has

584 been also described to act via suppression of JNK (9). These results suggest that factors

585 other than a FAO increase per se are responsible for ROS production and inflammation.

586 Accumulation of toxic substances (diacylglycerol or ceramides) (49), hypoxia (15), as

587 well as cytokines (42) might participate in the induction of ROS damage and the 
588 inflammatory state. Several researchers have demonstrated that enhanced FAO through

589 CPT1A or CPT1AM expression results in a decrease in relevant lipid mediators 590 involved in inflammation and insulin resistance such as diacylglycerol, intracellular 591 NEFAs (non-esterified FA), free FA, ceramides and TG $(3,9,13,26,29,40,45)$. While 592 some authors (3) didn’t see changes in skeletal muscle acylcarnitines' profile our group 593 has shown an increase in several acylcarnitines in CPT1AM-expressing neurons (25).

$594 \quad$ FA undergoing $\beta$-oxidation yield acetyl-CoA moieties that have two main 595 possible fates: (1) entry to the Krebs cycle for complete oxidation and ATP production, 596 or (2) conversion to ketone bodies (mainly in the liver). We observed increased FAO to $597 \mathrm{CO}_{2}$ and acid soluble products in CPT1AM-expressing adipocytes and macrophages. 598 CPT1AM expression in liver has been shown to enhance ATP and ketone bodies 599 production with no changes in glucose oxidation (29), (13). Altogether, this indicates a 600 metabolic rate switch towards FA.

601 Monocytes were the first immune cells reported to infiltrate obese adipose 602 tissue, differentiate to macrophages, produce inflammatory cytokines and trigger insulin 603 resistance $(56,57)$. Thus, we examined whether CPT1AM expression could play a 604 protective role in obesity-induced macrophage derangements. We found that, in human 605 WAT, CPT1A is highly expressed in SVF compared to adipocytes. This happened both 606 in human VAT and SAT. A closer histological and immunofluorescence examination 607 showed that macrophages present in the adipose tissue expressed CPT1A. This does not 608 rule out CPT1A expression in other immune cells also present in the adipose tissue such 609 as T and B cells, T regulatory cells, and mast cells.

610 Given the high CPT1A expression in human adipose tissue macrophages, we 611 decided to study the effect of CPT1AM in RAW 264.7 macrophages. A permanently 612 enhanced FAO rate in CPT1AM-expressing macrophages led to a complete restoration 
613 of palmitate-induced increase in TG content, and a decrease in inflammation, ER and

614 oxidative stress without affecting cell viability. Recent data show that FAO is capable 615 of regulating the degree of acyl chain saturation in ER phospholipids (28). Since 616 increasing the degree of saturation in ER phospholipids has been described to directly 617 activate ER stress and inflammation (28) this might provide a mechanistic link to how 618 FAO alleviates ER stress under palmitate loading. Thus, enhancing CPT1A expression 619 in macrophages may be a potential approach to fight against obesity-induced disorders.

620 In conclusion, we have shown that CPT1A expression was higher in human 621 adipose tissue macrophages than in mature adipocytes and that it was differentially 622 expressed in VAT vs. SAT. Further in vitro studies demonstrated that an increase in 623 FAO in lipid-treated adipocytes and macrophages reduced TG content and 624 inflammatory levels, improved insulin sensitivity in adipocytes, and reduced ER stress 625 and ROS damage in macrophages. Adipocyte specific knockout or transgenic animal 626 models for CPT1A would be especially relevant to elucidate its potential protection 627 against obesity-induced insulin resistance in vivo. Our data support the hypothesis that 628 pharmacological or genetic strategies to enhance FAO may be beneficial for the 629 treatment of chronic inflammatory pathologies such as obesity and T2D.

630 


\section{Funding}

632 This study was supported by the Spanish Ministry of Science and Innovation (Grants 633 SAF2010-20039 and SAF2013-45887-R to LH, SAF2011-30520-C02-01 to DS, 634 PI11/00085 to JJV, SAF2012-33014 to BP, SAF2012-36186 to SF-V, SAF2012-30708 635 to MVC, SAF2011-23626 to FV and doctoral fellowships to MIM and JFM), by the 636 CIBER Fisiopatología de la Obesidad y la Nutrición (CIBERobn) (Grant CB06/03/0001 637 to DS) and CIBER Diabetes y Enfermedades Metabólicas Asociadas (CIBERDEM) 638 (Grant CB07/08/0003 to MVC), Instituto de Salud Carlos III, by the European Union 639 (BetaBat project FP7-277713 to FV), by the European Foundation for the Study of 640 Diabetes (EFSD)/Lilly and EFSD/Janssen-Rising Star research fellowships to LH and 641 by the L'Oréal-UNESCO "For Women in Science" research fellowship to LH. MW is a 642 recipient of the Ciência sem Fronteiras-CNPq fellowship (237976/2012-9).

\section{Acknowledgements}

645 We thank Professor F.G. Hegardt and Dr. G. Asins for helpful comments and 646 suggestions, A. Orozco for technical assistance and R. Rycroft from the Language 647 Service of the University of Barcelona for valuable assistance in the preparation of the 648 English manuscript. We also thank D. Orlicky for kindly providing 3T3-L1 CAR $\Delta 1$ 649 adipocytes. SF-V acknowledges support from the "Miguel Servet" tenure track program 650 (CP10/00438) from the Fondo de Investigación Sanitaria (FIS) and co-financed by the 651 European Regional Development Fund (ERDF).

652

\section{Contribution statement}

654 All the authors contributed to the conception and design of the study. MIM, RF, 655 MW, MCD, JFM, LV, XE, MG-S, BP and LS carried out the experiments. All authors 
656 contributed to the analysis and interpretation of data and revising it critically for 657 important intellectual content. MIM, RF, MCD, JFM, BP, JJV and LH wrote the 658 manuscript. All authors revised and approved the final manuscript.

659

660

661

662 
664 1. Bosello O, Zamboni M. Visceral obesity and metabolic syndrome. Obes Rev 1: $665 \quad 47-56,2000$.

666

667

668

669

670

671

672

673

674

675

676

677

678

679

680

681

682

683

684

685

686

687

688

689

690

691

692

693

694

695

696

697

698

699

2. Brown NF, Hill JK, Esser V, Kirkland JL, Corkey BE, Foster DW, Garry JDMC. Mouse white adipocytes and 3T3-L1 cells display an anomalous pattern of carnitine palmitoyltransferase (CPT) I isoform expression during differentiation. Biochem J 231: 225-231, 1997.

\section{Bruce CR, Hoy AJ, Turner N, Watt MJ, Allen TL, Carpenter K, Cooney} GJ, Febbraio $M$ a, Kraegen EW. Overexpression of carnitine palmitoyltransferase-1 in skeletal muscle is sufficient to enhance fatty acid oxidation and improve high-fat diet-induced insulin resistance. Diabetes 58: 550 $8,2009$.

4. Bruce CR, Hoy AJ, Turner N, Watt MJ, Allen TL, Carpenter K, Cooney GJ, Febbraio MA, Kraegen EW. Overexpression of carnitine palmitoyltransferase-1 in skeletal muscle is sufficient to enhance fatty acid oxidation and improve high-fat diet-induced insulin resistance. Diabetes 58: 550 8, 2009.

5. Davies LC, Jenkins SJ, Allen JE, Taylor PR. Tissue-resident macrophages. Nat Immunol 14: 986-95, 2013.

6. Doh K-O, Kim Y-W, Park S-Y, Lee S-K, Park JS, Kim J-Y. Interrelation between long-chain fatty acid oxidation rate and carnitine palmitoyltransferase 1 activity with different isoforms in rat tissues. Life Sci 77: 435-43, 2005.

7. Feuerer M, Herrero L, Cipolletta D, Naaz A, Wong J, Nayer A, Lee J, Goldfine AB, Benoist C, Shoelson S, Mathis D. Lean, but not obese, fat is enriched for a unique population of regulatory $\mathrm{T}$ cells that affect metabolic parameters. Nat Med 15: 930-939, 2009.

8. Furukawa S, Fujita T, Shimabukuro M, Iwaki M, Yamada Y, Nakajima Y, Nakayama O, Makishima M, Matsuda M, Shimomura I. Increased oxidative stress in obesity and its impact on metabolic syndrome. J Clin Invest 114: 1752 1761, 2004.

9. Gao X, Li K, Hui X, Kong X, Sweeney G, Wang Y, Xu A, Teng M, Liu P, Wu D. Carnitine palmitoyltransferase $1 \mathrm{~A}$ prevents fatty acid-induced adipocyte dysfunction through suppression of c-Jun N-terminal kinase. Biochem J 435: 723-732, 2011.

10. Gesta S, Bezy O, Mori MA, Macotela Y, Lee KY, Kahn CR. Mesodermal developmental gene Tbx15 impairs adipocyte differentiation and mitochondrial respiration. Proc Natl Acad Sci U S A 108: 2771-6, 2011. 
733

734

735 736

11. Hamada Y, Nagasaki H, Fujiya A, Seino Y, Shang Q-L, Suzuki T, Hashimoto H, Oiso $\mathbf{Y}$. Involvement of de novo ceramide synthesis in proinflammatory adipokine secretion and adipocyte-macrophage interaction. $J$ Nutr Biochem 25: 1309-16, 2014.

12. Haslam DW, James WPT. Obesity. Lancet 366: 1197-1209, 2005.

13. Herrero L, Rubí B, Sebastián D, Serra D, Asins G, Maechler P, Prentki M, Hegardt FG. Alteration of the malonyl-CoA/carnitine palmitoyltransferase I interaction in the beta-cell impairs glucose-induced insulin secretion. Diabetes 54: 462-471, 2005.

14. Herrero L, Shapiro H, Nayer A, Lee J, Shoelson SE. Inflammation and adipose tissue macrophages in lipodystrophic mice. Proc Natl Acad Sci U S A 107: 240-245, 2010.

15. Hosogai N, Fukuhara A, Oshima K, Miyata Y, Tanaka S, Segawa K, Furukawa S, Tochino Y, Komuro R, Matsuda M, Shimomura I. Adipose tissue hypoxia in obesity and its impact on adipocytokine dysregulation. Diabetes 56: 901-911, 2007.

16. Hotamisligil GS. Endoplasmic reticulum stress and the inflammatory basis of metabolic disease. Cell 140: 900-17, 2010.

17. Houmard JA. Intramuscular lipid oxidation and obesity. Am J Physiol Regul Integr Comp Physiol 294: R1111-1116, 2008.

18. Huang S, Rutkowsky JM, Snodgrass RG, Ono-Moore KD, Schneider DA, Newman JW, Adams SH, Hwang DH. Saturated fatty acids activate TLRmediated proinflammatory signaling pathways. J Lipid Res 53: 2002-13, 2012.

19. Kelley DE, He J, Menshikova E V, Ritov VB. Dysfunction of Mitochondria in Human Skeletal Muscle in Type 2 Diabetes. Diabetes 51: 2944-2950, 2002.

20. Krishnan J, Danzer C, Simka T, Ukropec J, Walter KM, Kumpf S, Mirtschink P, Ukropcova B, Gasperikova D, Pedrazzini T, Krek W. Dietary obesity-associated Hifl $\alpha$ activation in adipocytes restricts fatty acid oxidation and energy expenditure via suppression of the Sirt2-NAD+ system. Genes Dev 26: 259-70, 2012.

21. Lin Y, Berg AH, Iyengar P, Lam TK, Giacca A, Combs TP, Rajala MW, Du X, Rollman B, Li W, Hawkins M, Barzilai N, Rhodes CJ, Fantus IG, Brownlee M, Scherer PE. The hyperglycemia-induced inflammatory response in adipocytes: the role of reactive oxygen species. $J$ Biol Chem 280: 4617-4626, 2005.

22. Mathis D. Immunological goings-on in visceral adipose tissue. Cell Metab 17: $851-9,2013$. 
750

751

752

753

754

755

756

757

758

759

760

761

762

763

764

765

766

767

768

769

770

771

772

773

774

775

776

23. Matsuzawa Y, Shimomura I, Nakamura T, Keno $\mathbf{Y}$, Tokunaga $\mathbf{K}$. Pathophysiology and pathogenesis of visceral fat obesity. Ann N Y Acad Sci 748: 399-406, 1995.

24. Matthews DR, Hosker JP, Rudenski AS, Naylor BA, Treacher DF, Turner RC. Homeostasis model assessment: insulin resistance and beta-cell function from fasting plasma glucose and insulin concentrations in man. Diabetologia 28: 412-419, 1985.

25. Mera P, Mir JF, Fabriàs G, Casas J, Costa ASH, Malandrino MI, Fernández-López J-A, Remesar X, Gao S, Chohnan S, Rodríguez-Peña MS, Petry H, Asins G, Hegardt FG, Herrero L, Serra D. Long-term increased carnitine palmitoyltransferase $1 \mathrm{~A}$ expression in ventromedial hypotalamus causes hyperphagia and alters the hypothalamic lipidomic profile. PLoS One 9: e97195, 2014.

26. Monsénégo J, Mansouri A, Akkaoui M, Lenoir V, Esnous C, Fauveau V, Tavernier V, Girard J, Prip-Buus C. Enhancing liver mitochondrial fatty acid oxidation capacity in obese mice improves insulin sensitivity independently of hepatic steatosis. J Hepatol 56: 632-639, 2012.

27. Morillas M, Gómez-Puertas P, Bentebibel A, Sellés E, Casals N, Valencia A, Hegardt FG, Asins G, Serra D. Identification of conserved amino acid residues in rat liver carnitine palmitoyltransferase I critical for malonyl-CoA inhibition. Mutation of methionine 593 abolishes malonyl-CoA inhibition. J Biol Chem 278: 9058-63, 2003.

28. Namgaladze D, Lips S, Leiker TJ, Murphy RC, Ekroos K, Ferreiros N, Geisslinger G, Brüne B. Inhibition of macrophage fatty acid $\beta$-oxidation exacerbates palmitate-induced inflammatory and endoplasmic reticulum stress responses. Diabetologia 57: 1067-1077, 2014.

29. Orellana-Gavalda JM, Herrero L, Malandrino MI, Paneda A, Sol Rodriguez-Pena M, Petry H, Asins G, Van Deventer S, Hegardt FG, Serra D. Molecular therapy for obesity and diabetes based on a long-term increase in hepatic fatty-acid oxidation. Hepatology 53: 821-832, 2011.

30. Orellana-Gavaldà JM, Herrero L, Malandrino MI, Pañeda A, Sol Rodríguez-Peña M, Petry H, Asins G, Van Deventer S, Hegardt FG, Serra D. Molecular therapy for obesity and diabetes based on a long-term increase in hepatic fatty-acid oxidation. Hepatology 53: 821-832, 2011.

31. Orlicky DJ, DeGregori J, Schaack J. Construction of stable coxsackievirus and adenovirus receptor-expressing 3T3-L1 cells. J Lipid Res 42: 910-915, 2001.

32. Patti M-E, Corvera S. The role of mitochondria in the pathogenesis of type 2 diabetes. Endocr Rev 31: 364-95, 2010.

33. Perdomo G, Commerford SR, Richard A-MT, Adams SH, Corkey BE, O'Doherty RM, Brown NF. Increased beta-oxidation in muscle cells enhances 
799

800

801

802

803

804

805

806

807

808

809

810

811

812

insulin-stimulated glucose metabolism and protects against fatty acid-induced insulin resistance despite intramyocellular lipid accumulation. J Biol Chem 279: 27177-27186, 2004.

34. Pérez-Pérez R, García-Santos E, Ortega-Delgado FJ, López JA, Camafeita E, Ricart W, Fernández-Real J-M, Peral B. Attenuated metabolism is a hallmark of obesity as revealed by comparative proteomic analysis of human omental adipose tissue. J Proteomics 75: 783-95, 2012.

35. Pessayre D, Fromenty B, Mansouri A. Mitochondrial injury in steatohepatitis. Eur J Gastroenterol Hepatol 16: 1095-1105, 2004.

36. Price N, van der Leij F, Jackson V, Corstorphine C, Thomson R, Sorensen A, Zammit V. A novel brain-expressed protein related to carnitine palmitoyltransferase I. Genomics 80: 433-442, 2002.

37. Ritov VB, Menshikova E V, He J, Ferrell RE, Goodpaster BH, Kelley DE. Deficiency of Subsarcolemmal Mitochondria in Obesity and Type 2 Diabetes. Diabetes 54: 8-14, 2004.

38. Rosen ED, Spiegelman BM. What We Talk About When We Talk About Fat. Cell 156: 20-44, 2014.

39. Samuel VT, Shulman GI. Mechanisms for insulin resistance: common threads and missing links. Cell 148: 852-71, 2012.

40. Sebastian D, Herrero L, Serra D, Asins G, Hegardt FG. CPT I overexpression protects L6E9 muscle cells from fatty acid-induced insulin resistance. Am J Physiol Endocrinol Metab 292: E677-86, 2007.

41. Sebastián D, Herrero L, Serra D, Asins G, Hegardt FG. CPT I overexpression protects L6E9 muscle cells from fatty acid-induced insulin resistance. Am J Physiol Endocrinol Metab 292: E677-86, 2007.

42. Shoelson SE, Herrero L, Naaz A. Obesity, inflammation, and insulin resistance. Gastroenterology 132: 2169-80, 2007.

43. Shoelson SE, Lee J, Goldfine AB. Inflammation and insulin resistance. $J$ Clin Invest 116: 1793-1801, 2006.

44. Simoneau JA, Veerkamp JH, Turcotte LP, Kelley DE. Markers of capacity to utilize fatty acids in human skeletal muscle: relation to insulin resistance and obesity and effects of weight loss. FASEB J 13: 2051-60, 1999.

45. Stefanovic-Racic M, Perdomo G, Mantell BS, Sipula IJ, Brown NF, O'Doherty RM. A moderate increase in carnitine palmitoyltransferase 1a activity is sufficient to substantially reduce hepatic triglyceride levels. Am J Physiol Endocrinol Metab 294: E969-77, 2008. 
813

814

815

816

817

818

819

820

821

822

823

824

825

826

827

828

829

830

831

832

833

834

835

836

837

838

839

840

841

842

843

844

845

846

847

848

849

850

46. Stefanovic-Racic M, Perdomo G, Mantell BS, Sipula IJ, Brown NF, O'Doherty RM. A moderate increase in carnitine palmitoyltransferase 1a activity is sufficient to substantially reduce hepatic triglyceride levels. Am J Physiol Endocrinol Metab 294: E969-977, 2008.

47. Suganami T, Nishida J, Ogawa $\mathbf{Y}$. A paracrine loop between adipocytes and macrophages aggravates inflammatory changes: role of free fatty acids and tumor necrosis factor alpha. Arterioscler Thromb Vasc Biol 25: 2062-8, 2005.

48. Suganami T, Tanimoto-Koyama K, Nishida J, Itoh M, Yuan X, Mizuarai S, Kotani H, Yamaoka S, Miyake K, Aoe S, Kamei Y, Ogawa Y. Role of the Toll-like receptor $4 / \mathrm{NF}-\mathrm{kappaB}$ pathway in saturated fatty acid-induced inflammatory changes in the interaction between adipocytes and macrophages. Arterioscler Thromb Vasc Biol 27: 84-91, 2007.

49. Summers SA. Ceramides in insulin resistance and lipotoxicity. Prog Lipid Res 45: 42-72, 2006.

50. Sun K, Kusminski CM, Scherer PE. Review series Adipose tissue remodeling and obesity. 121, 2011.

51. Sun K, Wernstedt Asterholm I, Kusminski CM, Bueno AC, Wang Z V, Pollard JW, Brekken R a, Scherer PE. Dichotomous effects of VEGF-A on adipose tissue dysfunction. Proc Natl Acad Sci U S A 109: 5874-5879, 2012.

52. Tran TT, Yamamoto Y, Gesta S, Kahn CR. Beneficial effects of subcutaneous fat transplantation on metabolism. Cell Metab 7: 410-420, 2008.

53. Villarroya F, Domingo P, Giralt M. Lipodystrophy in HIV 1-infected patients: lessons for obesity research. Int J Obes (Lond) 31: 1763-76, 2007.

54. Virtue S, Vidal-Puig A. Adipose tissue expandability, lipotoxicity and the Metabolic Syndrome--an allostatic perspective. Biochim Biophys Acta 1801: 338-49, 2010.

55. Wabitsch M, Brenner RE, Melzner I, Braun M, Moller P, Heinze E, Debatin KM, Hauner H. Characterization of a human preadipocyte cell strain with high capacity for adipose differentiation. Int J Obes Relat Metab Disord 25: 8-15, 2001.

56. Weisberg SP, McCann D, Desai M, Rosenbaum M, Leibel RL, Ferrante AW. Obesity is associated with macrophage accumulation in adipose tissue. $J$ Clin Invest 112: 1796-1808, 2003.

57. Xu H, Barnes GT, Yang Q, Tan G, Yang D, Chou CJ, Sole J, Nichols A, Ross JS, Tartaglia LA, Chen H. Chronic inflammation in fat plays a crucial role in the development of obesity-related insulin resistance. J Clin Invest 112: 1821-1830, 2003. 


\section{Tables}

852 Table 1. Clinical, analytical and CPT1A gene expression analysis of the obesity cohort. 853 BMI: Body mass index; sIL-6: soluble Interleukine-6; SBP: systolic blood pressure;

854 DBP: Diastolic blood pressure. Values are expressed as mean $\pm \mathrm{SD}$ or median 855 (interquartile range) for a non-Gaussian distributed variables. Differences vs. Lean: $856 * \mathrm{P}<0.001 ; \uparrow \mathrm{P}<0.05$. Differences vs. Overweight: $\# \mathrm{P}<0.001 ; \S \mathrm{P}<0.05$. $\dagger \mathrm{P}<0.05$ SAT vs. 857 VAT expression.

858

859 Table 2. Clinical, analytical and CPT1A gene expression analysis of the T2D cohort. 860 BMI: Body mass index; sIL-6: soluble Interleukine-6; SBP: systolic blood pressure;

861 DBP: Diastolic blood pressure. Values are expressed as mean $\pm \mathrm{SD}$ or median 862 (interquartile range) for a non-Gaussian distributed variables. Differences vs. controls: $863 * \mathrm{P}<0.001 ; \mathbb{P}<0.05$. Differences between SAT and VAT in the same group: $\uparrow \mathrm{P}=0.03$.

865 Table 3. Bivariate correlation analysis of CPT1A gene expression levels with several 866 genes in human VAT and SAT of the obesity cohort. PPAR- $\gamma$, Peroxisome proliferator867 activated receptor gamma; AGPAT5, 1-acylglycerol-3-phosphate O-acyltransferase 5; 868 SREBF1, sterol regulatory element binding transcription factor 1; BCL2, B-cell 869 CLL/lymphoma 2; CD163, macrophage and monocyte marker; $\mathrm{p}<0.005$ for all 870 correlations.

871

872 Table 4. Multiple regression analysis for CPT1A in VAT and SAT as dependent 873 variable in the obesity cohort. Independent variables included in the model: age, gender, 874 body mass index (BMI), peroxisome proliferator-activated receptor alpha (PPAR- $\alpha$ ), 875 peroxisome proliferator-activated receptor gamma (PPAR- $\gamma$ ), 1-acylglycerol-3- 
876 phosphate O-acyltransferase 5 (AGPAT5), sterol regulatory element binding 877 transcription factor 1 (SREBF1), B-cell CLL/lymphoma 2 (BCL2) and macrophage and 878 monocyte marker (CD163) gene expression levels. $\beta$ st: standardized beta coefficient. 879 CI: Confidence Interval.

880 


\section{$881 \quad$ Figure legends}

882 Fig. 1. CPT1 gene and protein expression in human adipose tissue. (A, B) CPT1A 883 relative mRNA levels in human VAT and SAT of the obesity (A) or the T2D (B) 884 cohort. Number of individuals: 19 lean, 28 overweight, 15 obese, 36 control and 11 885 T2D (See Table 1 and 2 for more details). (C, D) CPT1A protein levels in human VAT 886 and SAT of seven lean individuals (P1-P7) (C) and three obese individuals (D). (E, F) 887 CPT1B relative mRNA levels in human VAT and SAT of the obesity (E) or the T2D 888 (F) cohort. $* \mathrm{P}<0.05$.

889

890 Fig. 2. CPT1A is highly expressed in human adipose tissue macrophages. (A) CPT1A 891 mRNA levels in both adipose (AD) and stromal-vascular fraction (SVF) of human VAT 892 and SAT. $\mathrm{n}=4 .{ }^{*} \mathrm{P}<0.05$. (B) Immunohistochemical detection of CPT1A (brown) in 893 SAT of obese subjects. (C) Immunofluorescence staining of CPT1A (red) and CD68 894 (green) proteins in SAT of obese individuals. The counterstaining of nuclei (DAPI) is 895 shown in blue. Images are representative of adipose tissue preparations collected from 896 three subjects.

897

898 Fig. 3. Adenovirus infection efficiency and viability in 3T3-L1 CAR $\Delta 1$ adipocytes and 899 RAW 264.7 macrophages. Images were taken from (A) AdGFP-infected 3T3-L1 900 CAR $\Delta 1$ adipocytes (50\% infection) or (B) RAW 264.7 macrophages (70\% infection) $90148 \mathrm{~h}$ or $72 \mathrm{~h}$ after the infection, respectively. (C, D) Cell viability of (C) 3T3-L1 CAR $\Delta 1$ 902 adipocytes or (D) RAW 264.7 macrophages infected with AdGFP or AdCPT1AM and 903 incubated for $24 \mathrm{~h}$ with $1 \mathrm{mM}$ or $0.3 \mathrm{mM}$ palmitate (PA), respectively. 
905 Fig. 4 Enhanced FAO in 3T3-L1 CAR $\Delta 1$ adipocytes improves lipid-induced TG 906 accumulation, insulin sensitivity and inflammation. Relative CPT1A mRNA expression 907 (A) and protein levels (B) in AdGFP- or AdCPT1AM-infected 3T3-L1 CAR $\Delta 1$ 908 adipocytes. (C) CPT1 activity from mitochondria-enriched cell fractions incubated (or 909 not) with $100 \mu \mathrm{M}$ malonyl-CoA. (D) Total FAO rate represented as the sum of acid 910 soluble products plus $\mathrm{CO}_{2}$ oxidation. (E) TG content of adipocytes treated for $24 \mathrm{~h}$ with 911 1mM palmitate (PA). (F) Insulin signaling in GFP- and CPT1AM-expressing 912 adipocytes incubated with $0.3 \mathrm{mM}$ PA for $24 \mathrm{~h}$ as indicated by Western blotting of 913 insulin-induced Akt phosphorylation (pAkt) and IRbeta. (G) Quantification of pAkt 914 normalized by total Akt (fold change of arbitrary units, A.U.). (H) Quantification of 915 IRbeta normalized by $\beta$-actin. (I, J) Relative mRNA expression from GFP- or CPT1A916 expressing adipocytes incubated with $1 \mathrm{mM}$ PA for $24 \mathrm{~h}$. (K) Protein levels of IL-1 $\alpha$ in 917 the culture media of GFP- or CPT1A-expressing adipocytes incubated with $1 \mathrm{mM}$ PA 918 for $6 \mathrm{~h}$. Shown representative experiments out of 3 . $\mathrm{n}=3-6 .{ }^{*} \mathrm{P}<0.05$.

919

920 Fig. 5. Enhanced FAO and reduced TG content in CPT1AM-expressing RAW 264.7 921 macrophages. Relative CPT1A mRNA expression (A) and protein levels (B) in AdGFP922 or AdCPT1AM-infected macrophages. (C) CPT1 activity from mitochondria-enriched 923 cell fractions incubated (or not) with $100 \mu \mathrm{M}$ malonyl-CoA. (D) Total FAO rate 924 measured as the sum of acid soluble products plus $\mathrm{CO}_{2}$ oxidation. (E) TG content and 925 (F) Oil Red O staining of macrophages treated for $18 \mathrm{~h}$ with $0.75 \mathrm{mM}$ palmitate (PA). 926 Shown representative experiments out of $3 . \mathrm{n}=3-6 .{ }^{*} \mathrm{P}<0.05$.

927

928 Fig. 6. CPT1AM expression reduced inflammation, ER stress and ROS damage in 929 RAW 264.7 macrophages. (A, C, D) Relative mRNA gene expression from 
930 macrophages incubated with $0.5 \mathrm{mM}$ palmitate (PA) for $8 \mathrm{~h}(\mathrm{TNF}-\alpha$ and MCP-1) or 0.3

931 mM PA for 24 h (IL-10, Mgl-1, IL-4, IL-1 $\beta$, TLR-4, CHOP, GRP78, PDI and EDEM).

932 (B) Protein levels of IL-12p40 in the culture media of macrophages incubated with 0.3

$933 \mathrm{mM}$ PA for $24 \mathrm{~h}$. (E) CHOP protein levels and quantification in macrophages incubated

934 with $0.5 \mathrm{mM}$ PA for $8 \mathrm{~h} \mathrm{(F)} \mathrm{Protein} \mathrm{carbonyl} \mathrm{content} \mathrm{analysis} \mathrm{and} \mathrm{quantification} \mathrm{in}$ 935 macrophages incubated with $0.75 \mathrm{mM}$ PA for $18 \mathrm{~h}$. (G) Measurement of ROS

936 (superoxide) using the MitoSOX Red probe. Shown representative experiments out of $937 \quad 3 . \mathrm{n}=3-4 * \mathrm{P}<0.05$.

938 


\section{Table 1}

\begin{tabular}{|c|c|c|c|}
\hline & $\begin{array}{c}\text { Lean } \\
\text { BMI<25 } \\
(13 \text { male; } 6 \text { female })\end{array}$ & $\begin{array}{c}\text { Overweight } \\
\mathbf{2 5}=<\mathbf{B M I}<\mathbf{3 0} \\
(16 \text { male; } 12 \text { female })\end{array}$ & $\begin{array}{c}\text { Obese } \\
\text { BMI }>=\mathbf{3 0} \\
(9 \text { male; } 6 \text { female })\end{array}$ \\
\hline Age (years) & $51.7 \pm 16.0$ & $57.1 \pm 15.0$ & $57.4 \pm 12.8$ \\
\hline BMI $\left(\mathrm{kg} / \mathrm{m}^{2}\right)$ & $23.6(22.1-24.2)$ & $27.2(26.5-27.9)^{*}$ & $32.1(30.8-33.6)^{* \#}$ \\
\hline Waist (cm) & $83.0(79.0-90.0)$ & $97.0(90.5-100.0)^{*}$ & $107.0(100.0-117.2)^{* \#}$ \\
\hline Cholesterol (mM) & $5.2 \pm 1.2$ & $4.9 \pm 1.0$ & $5.2 \pm 0.8$ \\
\hline HDL-chol (mM) & $1.5 \pm 0.5$ & $1.3 \pm 0.3$ & $1.4 \pm 0.3$ \\
\hline Triglycerides (mM) & $1.0(0.7-1.6)$ & $1.1(0.8-1.5)$ & $1.0(0.7-1.3)$ \\
\hline Glucose (mM) & $4.8 \pm 0.7$ & $5.5 \pm 0.5^{*}$ & $5.6 \pm 0.5^{*}$ \\
\hline Insulin $(\mu \mathrm{IU} / \mathrm{ml})$ & $3.4(2.1-6.7)$ & $4.0(2.8-7.2)$ & $6.6(4.5-16.5) \pi$ \\
\hline HOMA-IR & $0.75(0.54-1.83)$ & $1.01(0.52-2.09)$ & $1.60(1.19-4.79) \rrbracket$ \\
\hline sIL-6 (pg/ml) & $1.4(1.1-2.5)$ & $1.0(0.7-2.2)$ & $2.5(1.4-5.2) \S$ \\
\hline SBP (mmHg) & $120(120-127)$ & $130(121-140)$ & $145(130-160) * \S$ \\
\hline DBP (mmHg) & $70(60-80)$ & $70(70-80)$ & $80(78-90) \pi$ \\
\hline SAT CPTIA & $0.85(0.66-1.14)^{\dagger}$ & $1.15(0.85-1.60)^{\dagger}$ & $0.86(0.72-1.81)$ \\
\hline VAT $C P T I A$ & $1.31(1.07-2.50)$ & $1.42(0.97-3.00)$ & $1.07(0.84-1.76)$ \\
\hline
\end{tabular}




\section{Control}

(21 male, 15 female)

Age (years)
BMI $\left(\mathrm{kg} / \mathrm{m}^{2}\right)$
Waist $(\mathrm{cm})$
Cholesterol $(\mathrm{mM})$
HDL-chol $(\mathrm{mM})$
Triglycerides $(\mathrm{mM})$
NEFA $(\mu \mathrm{M})$
Glycerol $(\mu \mathrm{M})$
Glucose $(\mathrm{mM})$
Insulin $(\mu \mathrm{IU} / \mathrm{ml})$
HOMA-IR
sIL-6 $(\mathrm{pg} / \mathrm{ml})$
SBP $(\mathrm{mmHg})$
DBP $(\mathrm{mmHg})$
SAT $C P T 1 A$
VAT $C P T 1 A$

$\begin{array}{cc}61.6 \pm 10.6 & 66.1 \pm 8.6 \\ 28.6(27.0-31.5) & 28.7(26.9-30.4) \\ 100.0(94.0-107.0) & 97.0(94.0-102.0) \\ 5.1 \pm 0.9 & 4.7 \pm 1.2 \\ 1.4(1.2-1.6) & 1.2(1.0-1.9) \\ 1.0(0.7-1.5) & 1.7(1.2-2.3) \rrbracket \\ 775.5 \pm 275.1 & 926.4 \pm 412.3 \\ 135.2(117.2-222.3) & 301.6(209.6-465.3) \\ 5.6(5.3-5.8) & 8.3(7.0-10.1)^{*} \\ 4.5(3.5-7.7) & 10.2(3.5-21.4) \\ 1.22(0.89-2.10) & 3.66(1.71-23.66) \\ 1.4(1.0-2.6) & 1.5(1.0-2.4) \\ 140(130-150) & 140(124-156) \\ 80(70-80) & 80(63-83) \\ 1.08(0.79-1.59) \dagger & 1.70(1.03-2.18) \\ 1.39(0.87-2.28) & 1.57(0.98-1.96)\end{array}$

\section{Type2 Diabetes}

(5 male, 6 female) 


\section{Table 3}

\begin{tabular}{lcc} 
& \multicolumn{2}{c}{ CPT1A } \\
\cline { 2 - 3 } & SAT & VAT \\
& $\mathbf{R}$ & $\mathbf{R}$ \\
\hline PPAR- $\gamma$ & -0.382 & \\
AGPAT5 & 0.639 & 0.714 \\
SREBF1 & 0.525 & 0.757 \\
BCL2 & 0.639 & 0.580 \\
CD163 & 0.731 & 0.716
\end{tabular}




\section{Table 4}

SAT ( $\mathrm{R}^{2}$ of the model: 0.71$)$

\begin{tabular}{|c|c|c|c|}
\hline Independent variables & B $(95 \% \mathrm{CI})$ & $\beta$ st & $p$ \\
\hline CD163 & $0.34(0.20-0.49)$ & 0.446 & $<0.0001$ \\
\hline AGPAT5 & $0.64(0.33-0.95)$ & 0.345 & $<0.0001$ \\
\hline SREBF1 & $0.19(0.06-0.33)$ & 0.245 & 0.006 \\
\hline \multicolumn{4}{|c|}{ VAT ( $\mathrm{R}^{2}$ of the model: 0.70$)$} \\
\hline Independent variables & B $(95 \%$ CI $)$ & $\beta$ st & $p$ \\
\hline CD163 & $0.34(0.21-0.48)$ & 0.569 & $<0.0001$ \\
\hline Age & $-0.15(-0-025--0.004)$ & -0.22 & 0.006 \\
\hline SREBF1 & $0.413(0.13-0.69)$ & 0.323 & 0.005 \\
\hline PPAR- $\gamma$ & $-0.29(-0.53--0.05)$ & -0.19 & 0.017 \\
\hline
\end{tabular}


Figure 1

A

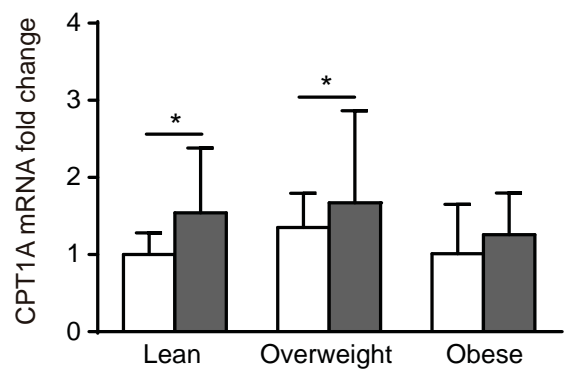

C
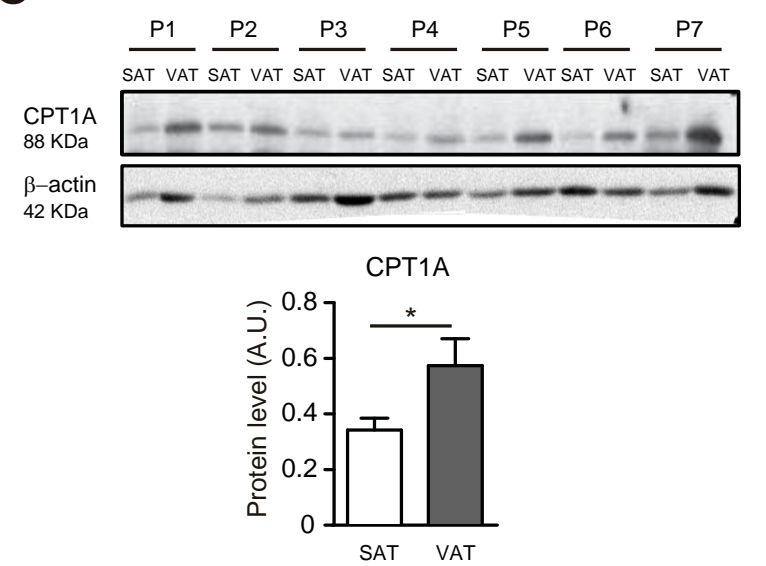

E

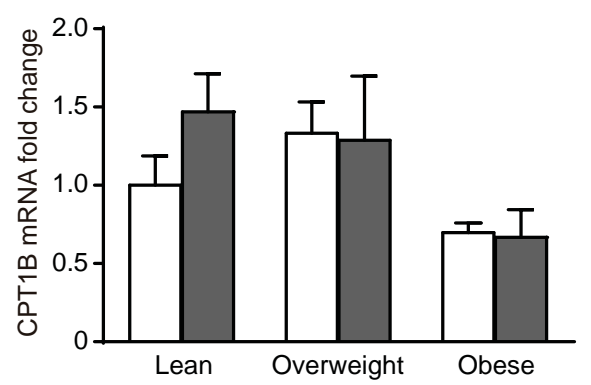

B

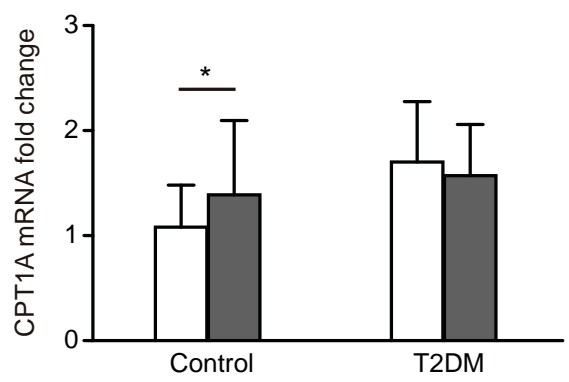

D

Obese

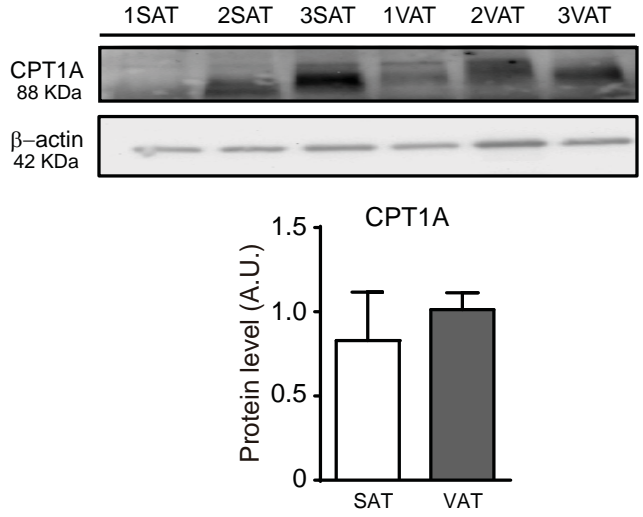

F

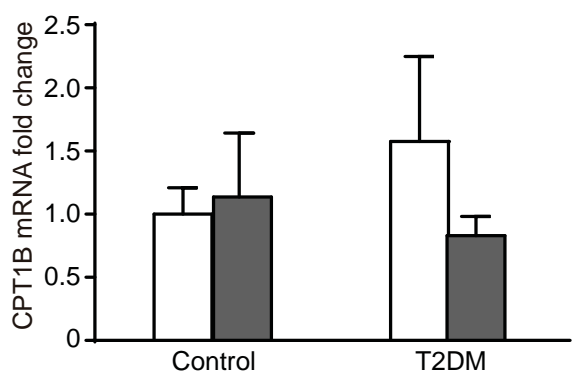


Figure 2
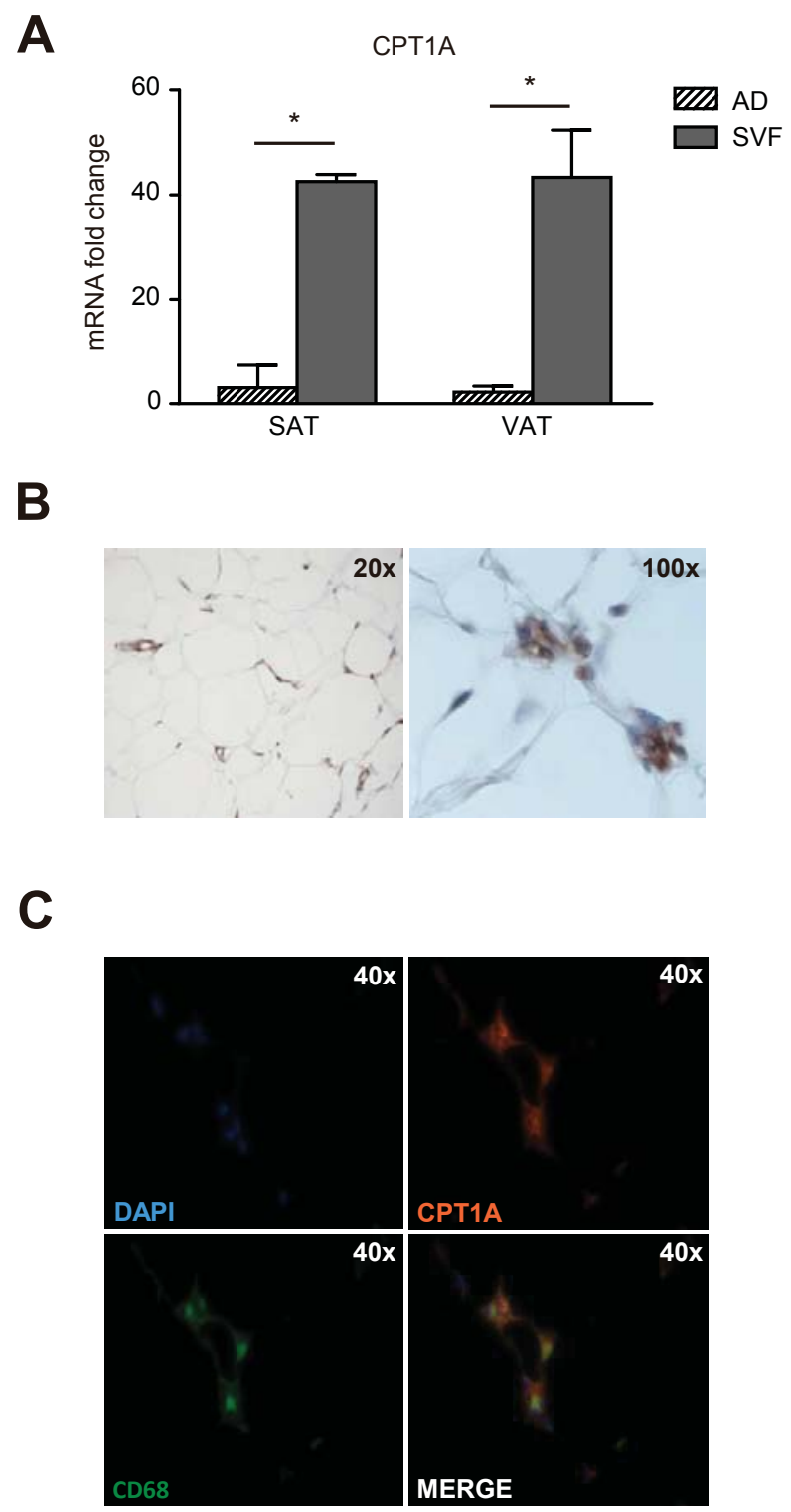
Figure 3

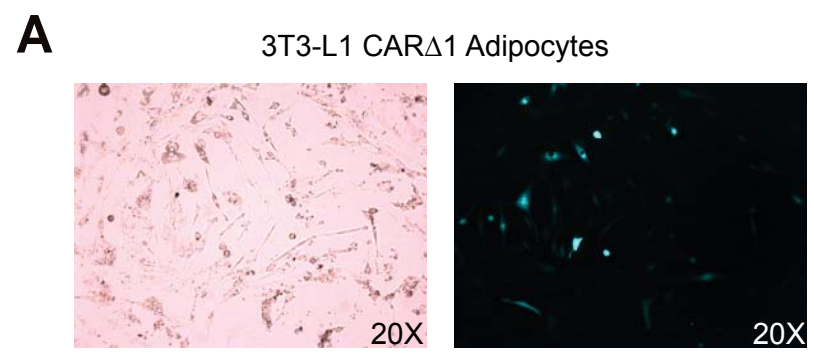

B

RAW 264.7 Macrophages
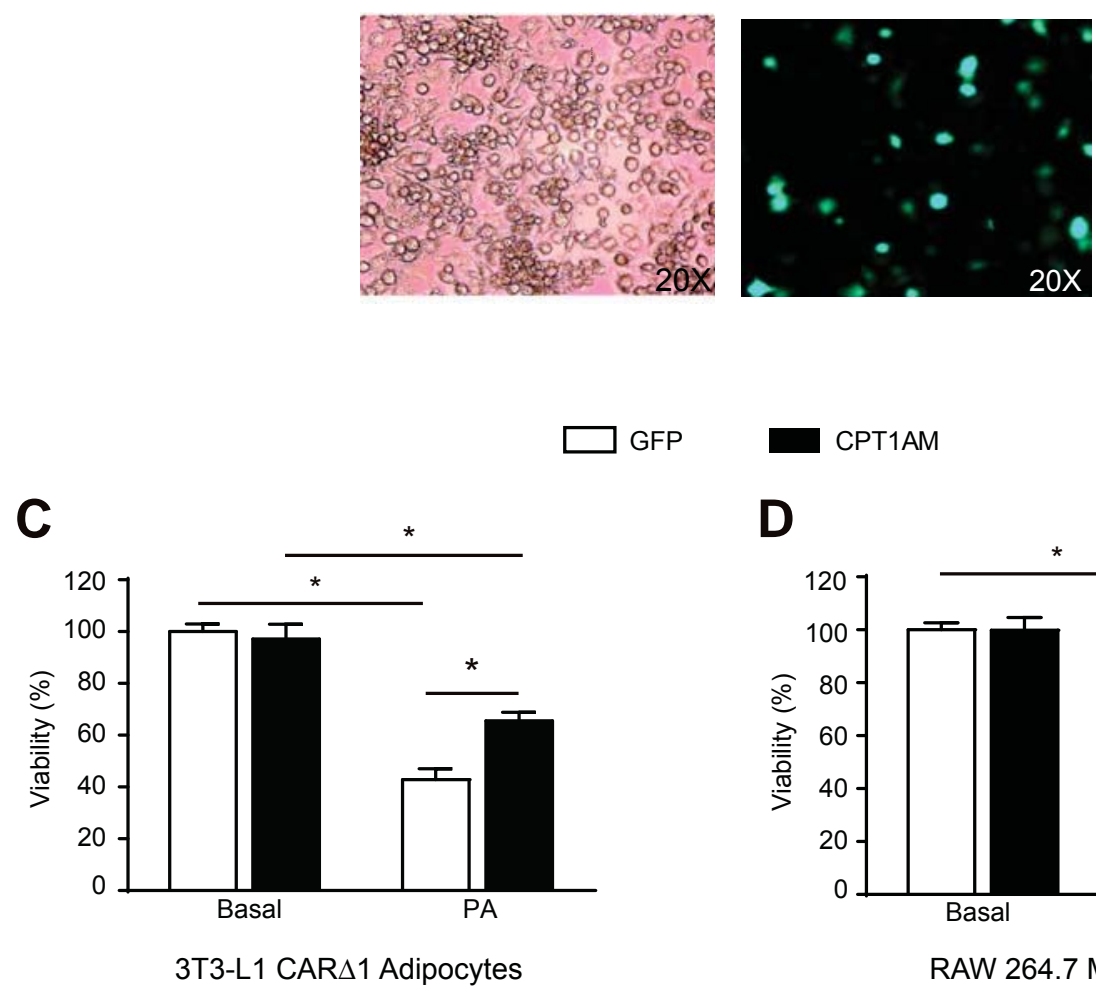

CPT1AM

D

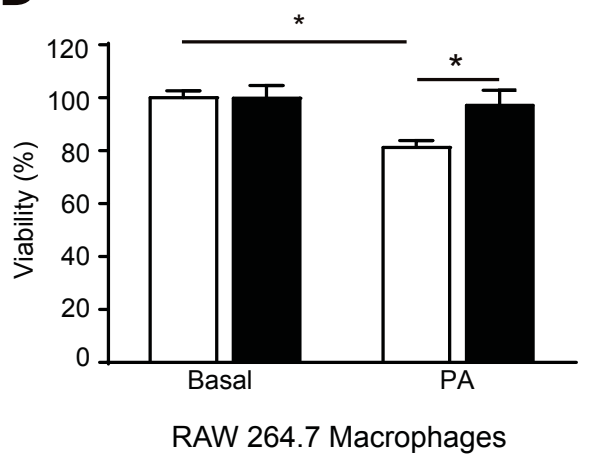


Figure 4

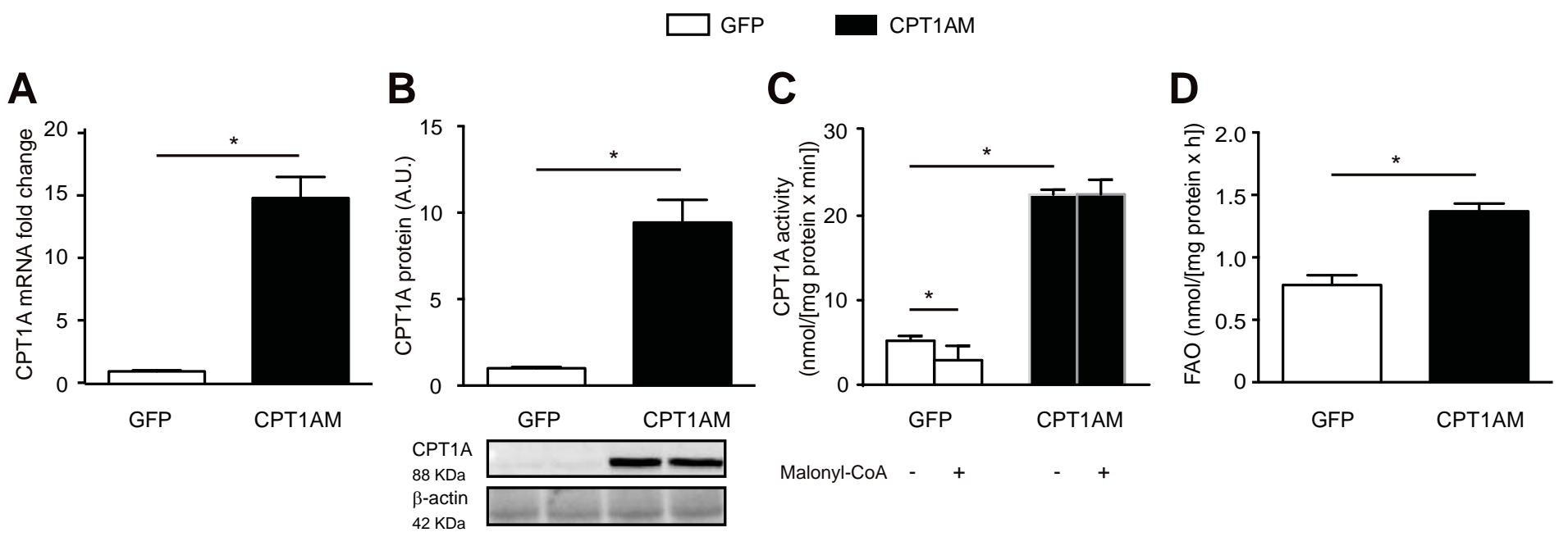

E

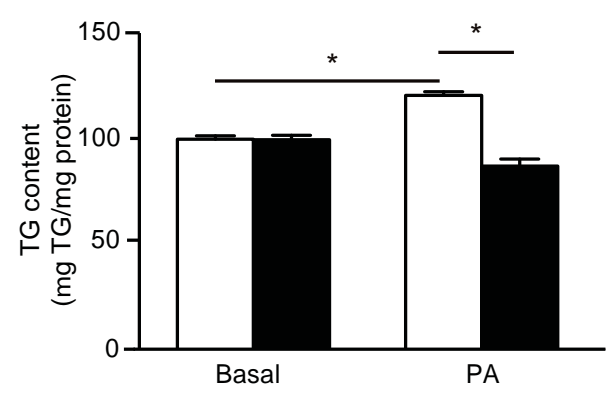

G

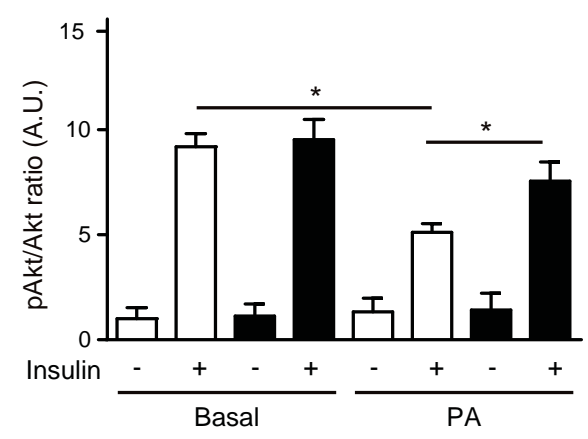

F

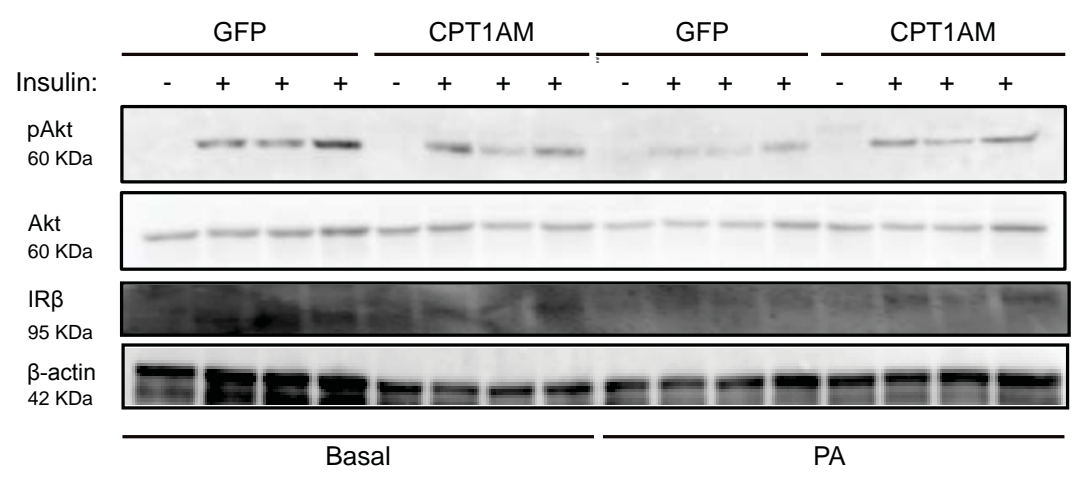

H

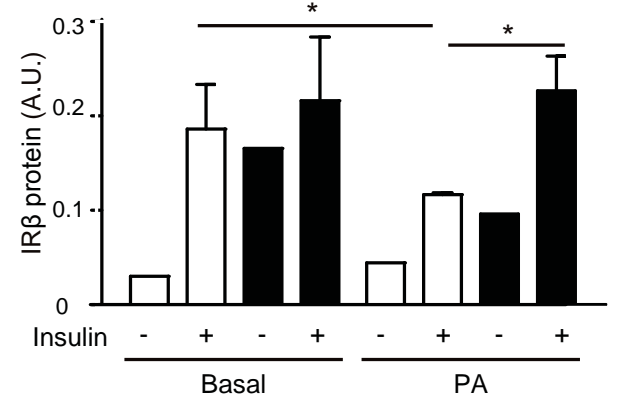

K

MCP-1

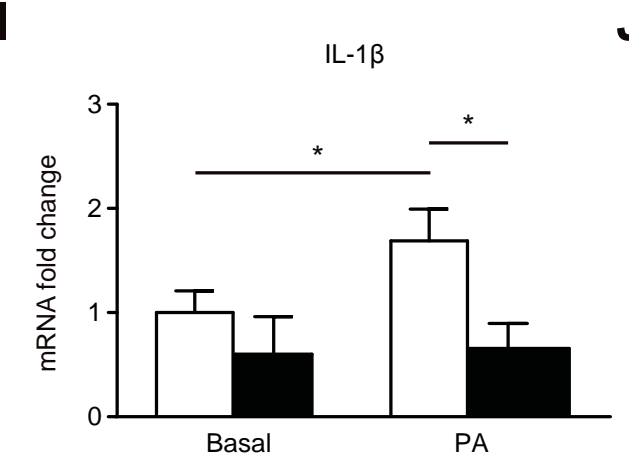

J

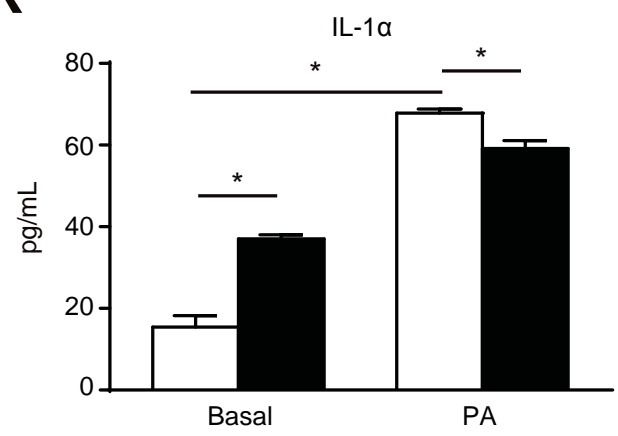


Figure 5
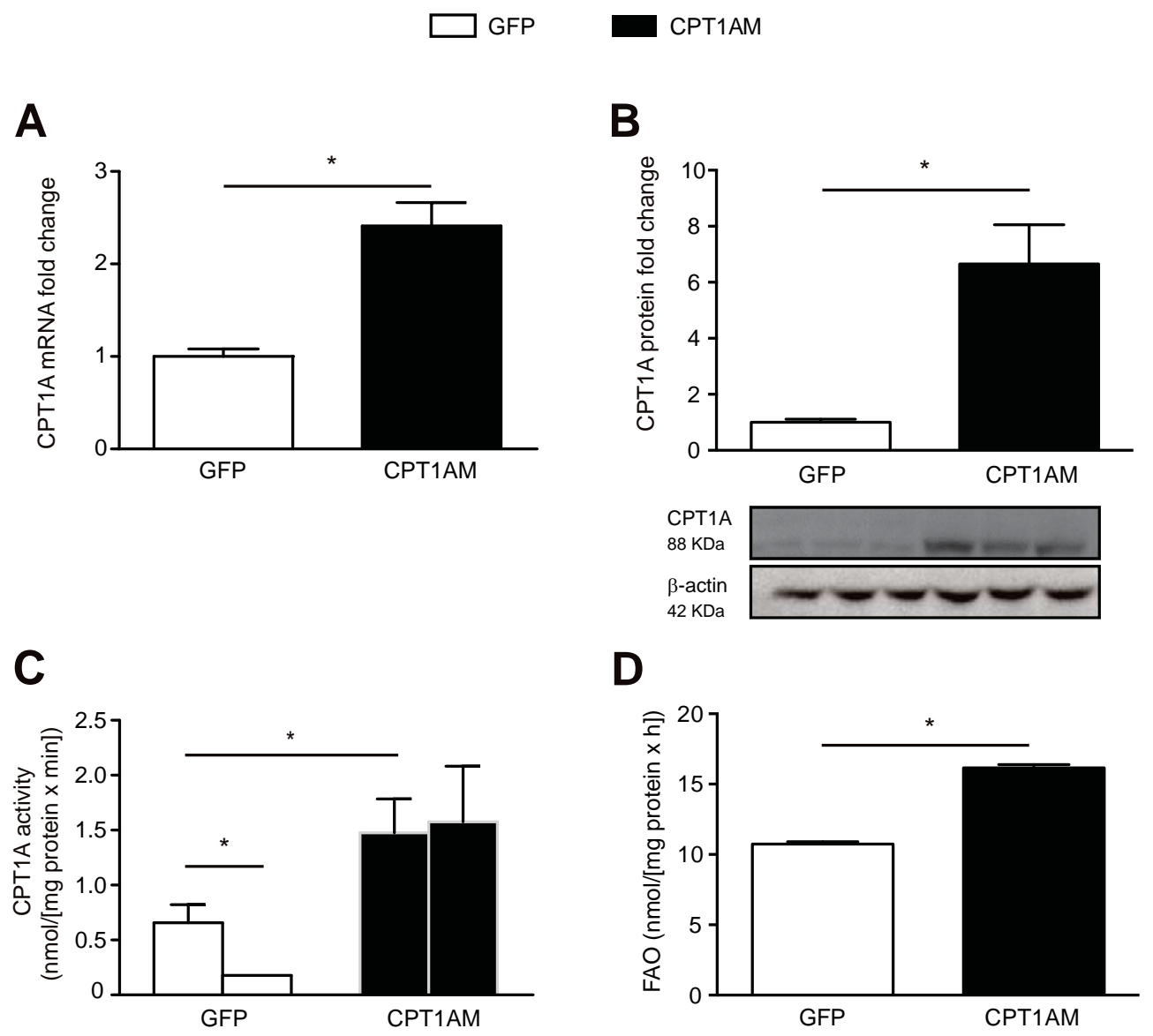

Malonyl-CoA - $\quad+\quad+\quad+$

E

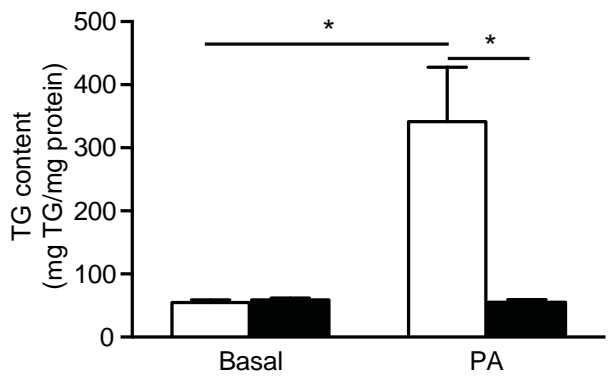

F

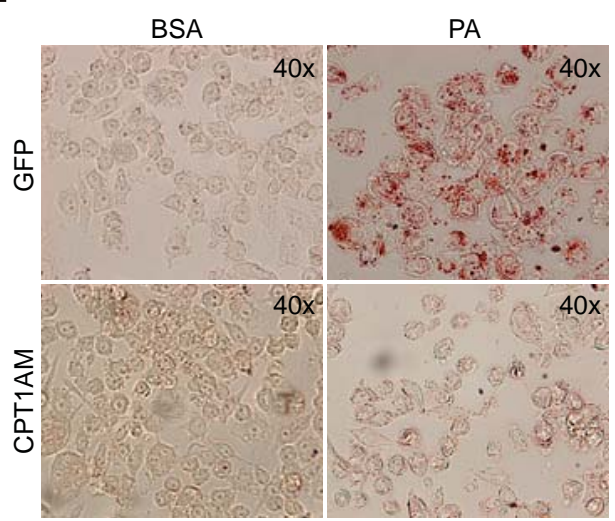


Figure 6

$\square$ GFP

A

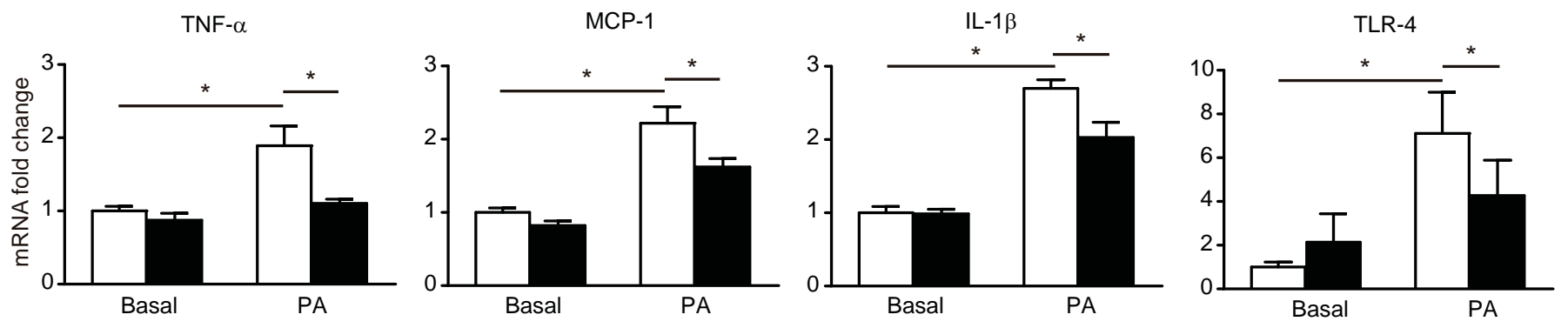

B

IL-12p40

C

IL-10

Mgl-1

IL-4
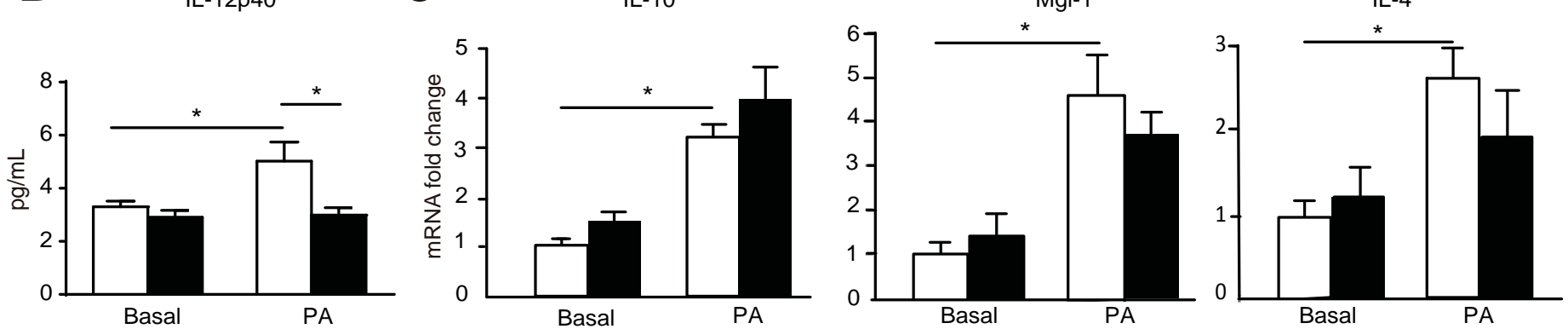

D
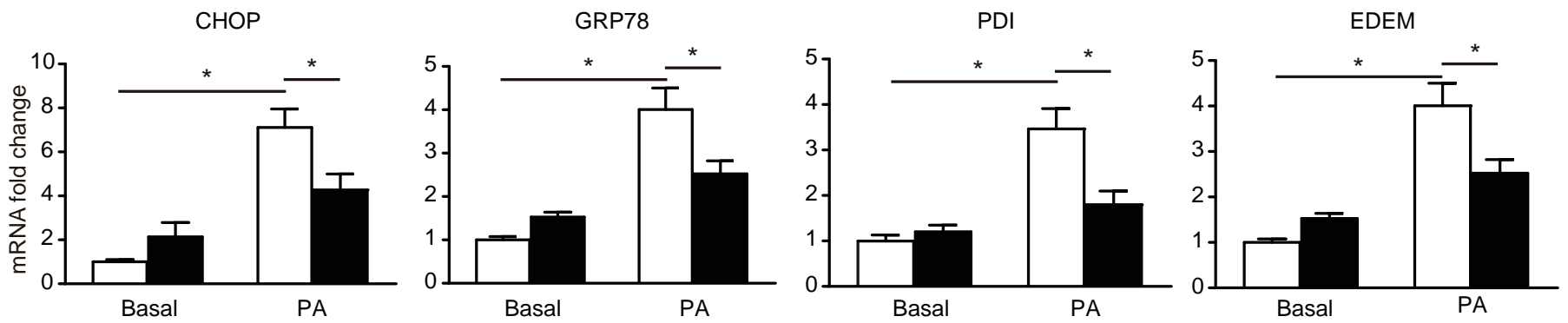

E

F

G

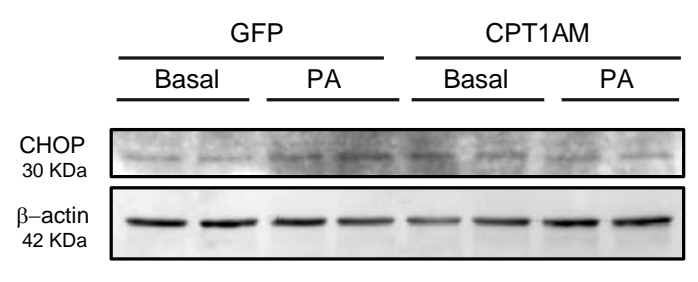

CHOP

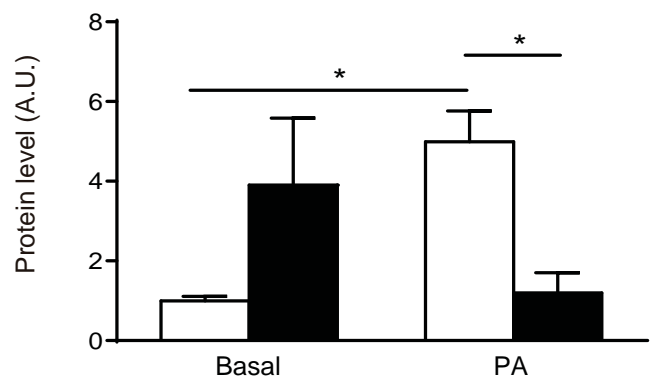

$\underline{\text { GFP }}$ CPT1AM GFP CPT1AM
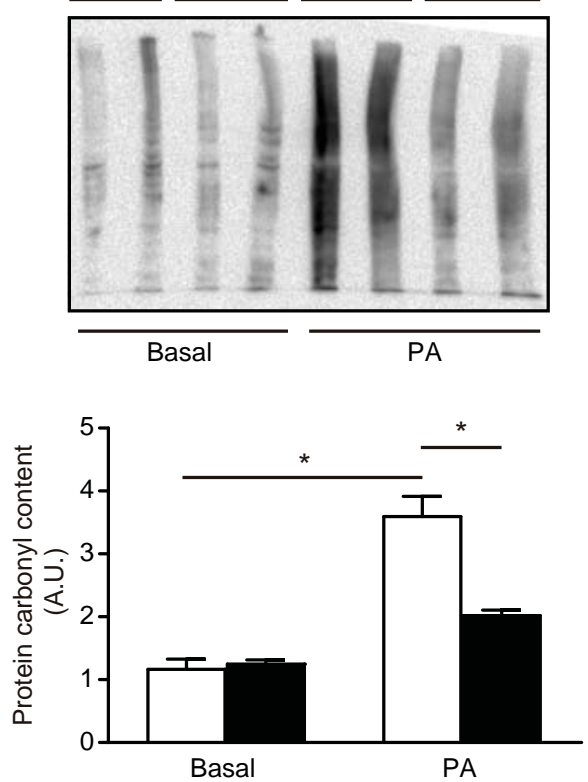

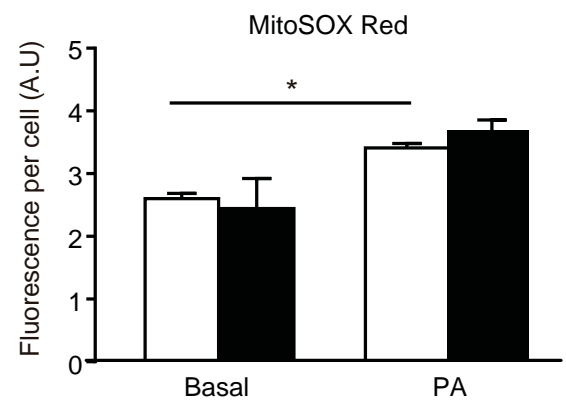

